\title{
Moral Character in the Workplace
}

Taya R. Cohen ${ }^{1}$, A. T. Panter ${ }^{2}$, Nazlı Turan ${ }^{3}$, Lily Morse ${ }^{1}, \&$ Yeonjeong Kim ${ }^{1}$

${ }^{1}$ Carnegie Mellon University, ${ }^{2}$ University of North Carolina at Chapel Hill,

${ }^{3}$ Católica Lisbon School of Business and Economics

Corresponding Author: Taya R. Cohen, Tepper School of Business, Carnegie Mellon

University, 5000 Forbes Ave., Pittsburgh, PA 15213. E-mail: tcohen@cmu.edu

Acknowledgments: This work was made possible through the support of the Berkman Faculty

Development Fund at Carnegie Mellon University, and a grant from The Character Project at Wake Forest University and the John Templeton Foundation to Taya R. Cohen and A. T. Panter

(Grant ID\# 15519). The opinions expressed in this publication are those of the authors and do not necessarily reflect the views of the sponsors. We thank the members of The Character Project at Wake Forest University for valuable feedback on this research.

Cohen, T. R., Panter, A. T., Turan, N., Morse, L. A., \& Kim, Y. (2014). Moral character in the workplace. Journal of Personality and Social Psychology. doi: 10.1037/a0037245

Published version available at: http://dx.doi.org/10.1037/a0037245

This article may not exactly replicate the final version published in the APA journal. It is not the copy of record. 


\begin{abstract}
In two three-month diary studies and a large cross-sectional survey, we identified distinguishing features of adults with low versus high levels of moral character. Adults with high levels of moral character tend to consider the needs and interests of others and how their actions affect other people (e.g., they have high levels of Honesty-Humility, empathic concern, guilt proneness), regulate their behavior effectively, specifically with reference to behaviors that have positive short-term consequences but negative long-term consequences (e.g., they have high levels of Conscientiousness, self-control, consideration of future consequences), and value being moral (e.g., they have high levels of moral identity-internalization). Cognitive moral development, Emotionality, and social value orientation were found to be relatively undiagnostic of moral character. Studies 1 and 2 revealed that low-moral-character employees committed harmful work behaviors more frequently and helpful work behaviors less frequently than highmoral-character employees, according to their own admissions and coworkers' observations. Study 3 revealed that low-moral-character adults committed more delinquent behavior and had more lenient attitudes toward unethical negotiation tactics as compared to high-moral-character adults. By showing that individual differences have consistent, meaningful effects on employees' behaviors, after controlling for demographic variables (e.g., gender, age, income) and basic attributes of the work setting (e.g., enforcement of an ethics code), our results contest situationist perspectives that de-emphasize the importance of personality. Moral people can be identified by self-reports in surveys, and these self-reports predict consequential behaviors months after the initial assessment.
\end{abstract}

Keywords: moral character; unethical behavior; counterproductive work behavior; organizational citizenship behavior; personality; delinquency; 


\section{Moral Character in the Workplace}

What aspects of a person are indicative of moral character? Although this question has been discussed by psychologists for close to a century, little theoretical or empirical consensus has emerged about the fundamental components of moral disposition (cf. Allport, 1937; Ashton \& Lee, 2007, Ashton, Lee, \& de Vries, 2014; Freud, 1961; Hogan, 1973, 1975; Lee \& Ashton, 2012; Narvaez \& Lapsley, 2009; Peterson \& Seligman, 2004). Some have challenged the notion that character traits exist or exert much influence on behavior, arguing instead that situational forces overwhelm individual differences (e.g., Bazerman \& Gino, 2012; Davis-Blake \& Pfeffer, 1989; Doris, 2002; Mischel, 1968; Ross \& Nisbett, 1991; Zimbardo, 2004). However, this argument is inconsistent with countless studies indicating that unethical behavior is constrained by a variety of broad and narrow traits (Ashton \& Lee, 2007, 2008a; Ashton et al., 2014; Berry, Carpenter, \& Barratt, 2012; Berry, Ones, \& Sackett, 2007; Cohen, Panter, \& Turan, 2012; Henle \& Gross, 2013; Kish-Gephart, Harrison, \& Treviño, 2010; Lee \& Ashton, 2012). It is clear from the vast empirical literature in social/personality and industrial/organizational psychology that the landscape of moral character is wide and varied, but we do not yet have an adequate map.

Knowledge about the relative importance of different traits for predicting moral behavior is critical for those making selection and promotion decisions in organizational contexts (e.g., managers making hiring decisions) and in academic settings (e.g., admissions committees deciding which applicants to accept). Indeed, the prevalence of integrity testing in organizations attests to institutions' long-standing interest in hiring, retaining, and promoting individuals who have strong moral character (Ones, Viswesvaran, \& Schmidt, 1993; Ones, Viswesvaran, \& Schmidt, 2012; Sackett \& Schmitt, 2012; Van Iddekinge, Roth, Raymark, \& Odle-Dusseau, 2012). Suppose a manager or human resource professional asked you, which traits are the most 
important to measure to predict who is likely to behave unethically at work, assuming time and resources are limited? There are a number of traits you might mention, but because empirical data relevant to answering this question is lacking, any answer you give would likely be unsatisfactory. With few exceptions, research has not comprehensively investigated a large set of moral character traits to determine the relative importance of each for behavioral prediction.

The lack of understanding about which traits should be conceptualized as moral character traits is problematic for theoretical reasons as well as practical ones. The central theoretical problem is that we do not know which individual differences are most diagnostic of character and predictive of moral behavior. The central practical problem is that the advice we can currently offer those who might wish to assess moral character is wanting.

\section{Defining Morality and Ethics}

Morality and ethics—-terms we use interchangeably—are notoriously difficult constructs to define (cf. Bazerman \& Gino, 2012; Brief, 2012; Gilligan, 1982; Graham, Nosek, Haidt, Iyer, Koleva, \& Ditto, 2011; Gray, Young, \& Waytz, 2012; Greene, 2013; Haidt, 2007; Hogan, 1973; Janoff-Bulman \& Carnes, 2013; Kohlberg, 1969; Rai \& Fiske, 2011; Tenbrunsel \& SmithCrowe, 2008; Treviño, den Nieuwenboer, \& Kish-Gephart, 2014). We use these terms to refer to standards of right and wrong conduct. Harmful acts, broadly construed, are the hallmarks of unethical/immoral behavior, whereas helpful acts, broadly construed, are the hallmarks of ethical/moral behavior. The centrality of harm and help to morality can be explained by the idea that morality is about regulating our social relationships (Greene, 2013; Haidt \& Kesebir, 2010; Janoff-Bulman \& Carnes, 2013; Rai \& Fiske, 2011) and by the dyadic agent-patient model of morality (Gray et al., 2012). 
According to the relationship regulation view, the purpose of morality is to facilitate and coordinate interpersonal relationships and group living "so as to optimize our existence as social beings" (Janoff-Bulman \& Carnes, 2013, p. 219; for similar perspectives, see Greene, 2013; Haidt \& Kesebir, 2010; Rai \& Fiske, 2011). Harmful behavior is central to morality because it hinders cooperation and group functioning, whereas helpful behavior is central to morality because it facilitates cooperation and group functioning.

Complementary to the relationship regulation view is the dyadic agent-patient model of morality, which proposes that harmful acts are committed by moral agents and these acts cause suffering to moral patients (Gray et al., 2012). This theory posits that we make moral judgments (i.e., label entities as good or bad) when agents and patients are perceived to have mental capacity. Notably, the suffering the agents cause to the patients can be abstract and indirect, and need not contain a physical component—all that is required is perceived suffering by some entity. This abstract, high-level view of harm as the superordinate factor underlying moral judgments allows the dyadic agent-patient model to account for diverse moral values, including those related to fairness, loyalty, authority, and purity.

In accordance with these perspectives, the criterion variables used in Studies 1 and 2 are intentional behaviors that harm or help organizations or people within them-counterproductive work behaviors (CWB) and organizational citizenship behaviors (OCB) (Fox \& Spector, 2005; Podsakoff, MacKenzie, \& Organ, 2005). We chose to examine organizational behaviors because the workplace affords employees with myriad opportunities to act ethically and unethically, and most adults spend a substantial portion of their lives at work. Moreover, there are established scales for measuring CWB and OCB, which are behaviors that adults consider immoral and moral, respectively. Examples of CWB include: being nasty or rude to clients or customers; 
taking supplies or tools home without permission; and leaving work earlier than one is allowed (Spector et al., 2006). Examples of OCB include: taking time to advise, coach, or mentor coworkers; lending a compassionate ear when someone has a work problem; and changing vacation schedules, work days, or shifts to accommodate coworkers' needs (Fox, Spector, Goh, Bruursema, \& Kessler, 2012). Consistent with the notion that harm and help are central to morality, a pilot study of more than 400 working adults that examined moral judgments of work behaviors confirmed our assumption that employees believe CWB is immoral and OCB is moral (see Appendix).

\section{Defining Moral Character}

We view character traits as the subset of personality traits that are relevant to morality and ethics. Accordingly, we define moral character as an individual's characteristic patterns of thought, emotion, and behavior associated with moral/ethical and immoral/unethical behavior. This definition is adapted from Funder and Fast's definition of personality (Funder \& Fast, 2010, p. 669): “an individual's characteristic patterns of thought, emotion, and behavior, together with the psychological mechanisms—-hidden or not—behind those patterns."

One reason for the ambiguity about which traits should be considered character traits is that the emphasis within moral psychology has been on how people make judgments in difficult dilemmas where there is no clear right or wrong choice, rather than on what predicts helpful and harmful behaviors in people's everyday lives, where the right versus wrong choice is more transparent. For instance, many scholars have used the trolley dilemma to study morality (e.g., Greene, 2013; Greene, Sommerville, Nystrom, Darley, \& Cohen, 2001)—a situation in which respondents must decide whether it is appropriate to murder one person (by a variety of means) to save five. Others have used variants of Kohlberg's dilemmas, such as the Heinz case (e.g., 
Rest, Narvaez, Thoma, \& Bebeau, 1999)—a situation in which respondents must decide whether Heinz should steal drugs to save his dying wife. In dilemmas such as these, moral values related to fairness, justice, harm, care, and loyalty are all at play, and often in conflict. As such, these dilemmas are effective tools for identifying the kinds of cognitive and emotional processes that inform judgments in situations where it is difficult to decide what is right and what is wrong (cf. Haidt, 2001; Haidt, 2010; Narvaez, 2010)_situations that philosophers refer to as dilemmas to highlight the fact there is no clear answer. However, as thought-provoking as philosophical moral dilemmas are, they might not be particularly helpful for understanding what predicts more mundane behaviors in which there is widespread agreement about the rightness or wrongness of the choices.

A second reason for the ambiguity surrounding the question of what traits should be conceptualized as moral character traits is that the majority of research programs restrict their inquiries to a small set rather than examine multiple aspects of personality simultaneously. When multiple aspects of personality are investigated together, it tends to be at the level of broad dimensions, such as in research examining the Big Five (e.g., Berry et al., 2012; Berry et al., 2007) or HEXACO factors (e.g., Ashton \& Lee, 2007, 2008a, 2008b; Ashton et al., 2014; Lee \& Ashton, 2012; Lee, Ashton, Morrison, Cordery, \& Dunlop, 2008; Marcus et al., 2007). Few studies of moral character and behavior have examined broad and narrow traits simultaneously. An exception is Peterson and Seligman's (2004) handbook on Character Strengths and Virtues. This work is grounded in positive psychology, and its stated goal is to develop a scientific classification of "positive individual traits" (p. 5). The character strengths Peterson and Seligman (2004) consider are wide-ranging, including humor, creativity, leadership and other socially desirable abilities and talents, along with individual differences that we assume are more 
relevant to predicting ethical and unethical behaviors, such as fairness, integrity, and self-control. Their expansive focus is in accordance with their goal of studying positive "character strengths," but an inherent downside of such an approach is that the construct of moral character becomes ill-defined and the classification of traits becomes unwieldy. For example, creativity is considered a character strength in Peterson and Seligman's classification system because it relates to the virtue of wisdom. However, empirical research shows that creativity facilitates unethical behavior by helping individuals justify it through inventive rationalizations (Gino \& Ariely, 2012). Thus, while creativity may indeed be a socially desirable trait and valued across cultures (Peterson \& Seligman, 2004), it does not seem appropriate to label it a moral character trait given that it is associated with greater dishonesty and cheating.

In contrast to Peterson and Seligman's (2004) expansive classification of strengths, we focus our investigation on personality traits that empirically predict ethical and unethical behaviors in people's everyday lives. Like Peterson and Seligman's approach, we take a trait theory view of moral character, assuming that "character is plural" and that character traits are "stable and general but also shaped by the individual's setting and thus capable of change" (Peterson \& Seligman, 2004, p. 10). By narrowing our attention to stable individual differences that predict harmful and helpful behaviors, we hope to gain a better handle on how moral character should be conceptualized and assessed. Unlike the previous work on character strengths, our research is not aimed at developing a new measurement instrument for assessing character (cf. Linley et al., 2007). Rather we seek to examine widely-used and empirically validated extant scales that have been theoretically and/or empirically linked to ethical choices in prior research. 


\section{Motivation, Ability, \& Identity Elements of Moral Character}

By concurrently assessing a wide array of individual differences, our work allows for the integration of a variety of research streams that heretofore have been studied in isolation. The supplemental online materials contain descriptions of the more than two dozen variables we investigated in the three studies reported here, along with descriptive statistics, alpha coefficients, test-retest reliability, and bivariate correlations among the variables. We selected variables by searching the social/personality and industrial/organizational psychology literatures for scales that theoretically or empirically relate to morality and ethics. A multitude of individual differences have been shown to correlate with unethical behavior, and our goal in this research was to be exploratory and as comprehensive as possible. Rather than testing a particular theoretical framework or limited set of variables, we instead sought to rigorously examine a diverse array of traits using a variety of methods and statistical techniques. ${ }^{1}$

We assume that moral character is not a single personality dimension, but rather a multifaceted construct comprised of broad and narrow traits. Broad traits might include HonestyHumility, Conscientiousness, Agreeableness, and/or Emotionality (Ashton \& Lee, 2007, 2008a, 2008b; Ashton et al., 2014; Berry et al., 2007, 2012; Henle \& Gross, 2013; Marcus et al., 2007), whereas more localized traits might include, among others, empathy (Batson et al., 2003; Hogan, 1973; Eisenberg, 2000), guilt proneness (Cohen et al., 2012; Tangney, Stuewig, \& Mashek, 2007; Tangney, Stuewig, \& Martinez, 2014), Machiavellianism (Christie \& Geis, 1970; KishGephart et al., 2010; Hegarty \& Simms, 1978; O’Boyle, Forsyth, Banks, \& McDaniel, 2012), self-control (Baumeister, Vohs, \& Tice, 2007; Gino, Schweitzer, Mead, \& Ariely, 2011; Tangney, Baumeister, \& Boone, 2004), and moral identity (Aquino \& Reed, 2002; Aquino, Freeman, Reed, \& Felps, 2009; Reed \& Aquino, 2003; Shao, Aquino, Freeman, 2008). 
Collectively, these individual differences could reduce harmful behaviors and foster helpful behaviors by bolstering one's motivation to be moral (e.g., consideration of others), ability to be moral (e.g., self-regulation), and/or identity as a moral person (e.g., desire to see oneself as moral).

Conceptualizing moral character as having motivational, ability, and identity elements is reminiscent of Robert Hogan's earlier theorizing that empathy, socialization, and autonomy are hallmarks of morally mature individuals (Hogan, 1973, 1975). In support of Hogan's theorizing, the positive relationship between empathy and helpful behavior is well-established, as is the negative relationship between empathy and harmful behavior (e.g., Batson et al., 2003; Eisenberg, 2000). Likewise, research linking Conscientiousness to moral behavior supports Hogan's theorizing that socialization is a key aspect of moral character (Berry et al., 2012; Berry et al., 2007; Marcus et al., 2007; Roberts, Jackson, Fayard, Edmonds, \& Meints, 2009). Specifically, similar to modern-day conceptions of Conscientiousness (Roberts et al., 2009), Hogan suggested that "a person may be considered socialized to the degree that he regards the rules, values, and prohibitions of his society as personally mandatory" (Hogan, 1973, p. 221). Finally, similar to modern-day conceptions of moral identity (Aquino \& Reed, 2002), Hogan pointed out that a person could refrain from cheating not because he is empathic or socialized, but rather because he considers "cheating to be beneath his dignity as a person" (Hogan, 1973, p. 226). Thus, Hogan's work suggests that the current research should reveal that traits related to empathy (e.g., empathic concern, perspective taking), socialization (e.g., Conscientiousness), and autonomy (e.g., moral identity-internalization) are particularly important facets of moral character. In the three studies that follow, we examine these traits as well as others that have been linked to unethical choices at work (Kish-Gephart et al., 2010), such as moral idealism 
(Forsyth, 1980), moral relativism (Forsyth, 1980), and cognitive moral development (Rest, 1986).

\section{Study 1 \& Study 2}

Study 1 and Study 2 report results from two three-month diary studies in which we examined how 22 individual differences relate to ethical and unethical work behaviors. Statistical analyses of these individual differences allow us to draw important theoretical insights into what makes a person moral. Furthermore, investigating whether moral character traits have consistent, meaningful effects on employees' work behaviors, after controlling for demographic characteristics and basic attributes of the work setting, allows us to test the credibility of situationist perspectives that de-emphasize the importance of personality in predicting behavior (cf. Bazerman \& Gino, 2012; Davis-Blake \& Pfeffer, 1989; Doris, 2002; Mischel, 1968; Ross \& Nisbett, 1991; Zimbardo, 2004).

The data in Study 1 and Study 2 come from the Work Experiences and Character Traits (WECT) Project (see www.WECTProject.org for a complete project description). There were two studies in the project; both had the same design. The core strengths of these studies are that we used multiple measures to describe the attributes of both high and low moral character adults, multiple reporters to understand how character is manifested in work behaviors, and longitudinal assessments to determine whether these relationships hold over time. Our samples were large (approximately 1,000 participants in Study 1 and approximately 500 participants in Study 2) and diverse-participants lived in all 50 states and worked in every occupational category classified by the U.S. Bureau of Labor Statistics, giving us confidence in the robustness and generalizability of our results. $^{2}$ 
We assessed CWB and OCB with self-reports and coworker reports. We assume that both methods provide valid information about employees' work behaviors and that the strengths and weaknesses of these methods are complementary (Berry et al., 2012; Vazire, 2010). People have more information about their own behavior than they do about others' behavior, and this is especially true of unethical behavior, given that employees tend to hide such behavior from others. Accordingly, we expect coworkers to under-report the amount of CWB that employees commit relative to the employees' self-reports (Berry et al., 2012). Although self-reports could be biased because CWB is socially undesirable and OCB is socially desirable (Vazire, 2010), we did not expect impression management to be a major concern in the current research given that all surveys were anonymous and completed online. Moreover, a meta-analysis of self-reports and other-reports of CWB found that: "self- and other-ratings of CWB were moderately to strongly correlated with each other"; "self- and other-report CWB exhibited very similar patterns and magnitudes of relationships with a set of common correlates"; and "other-report CWB generally accounted for little incremental variance in the common correlates beyond self-report CWB" (Berry et al., 2012, p. 613). In light of these meta-analytic findings, we hypothesized that selfreported moral character would predict CWB regardless of which assessment method was used to measure $\mathrm{CWB}$, and the same for OCB.

\section{Method}

\section{Participants}

Participants were members of an online panel administered by a private survey research firm. Study 1 lasted from September 2011 to December 2011 ( $N=1,020$, plus 215 coworkers); Study 2 lasted from January 2012 to April 2012 ( $N=$ 494, plus 126 coworkers). Participants in Study 1 were not eligible to participate in Study 2. These individuals were a diverse group of 
American adults living in all 50 U.S. states. Of the 1,514 employees who participated in the WECT Project (Studies 1 and 2 combined), half were women, and ages ranged from 18 to 71 years $(M=39.32$ years, $S D=11.37)$. The sample contained White $(75.2 \%)$, Black $(9.2 \%)$, Hispanic (5.5\%), Asian (3.6\%), and multiracial or other (6.3\%) participants, which roughly corresponds to U.S. census data (http://www.census.gov/prod/cen2010/briefs/c2010br-02.pdf). In regards to education, $51.1 \%$ had a Bachelor's degree or more, whereas $48.9 \%$ had less education than a Bachelor's degree.

The occupations that respondents reported represent all 23 occupational categories classified by the U.S. Bureau of Labor Statistics (U.S. Bureau of Labor Statistics, 2010, http://www.bls.gov/soc/\#materials). Specifically, 47.2\% worked in management, business, science, and arts occupations, $12.3 \%$ worked in service occupations, $18.1 \%$ worked in sales and office occupations, $5.4 \%$ worked in natural resources, construction, and maintenance occupations, $6.2 \%$ worked in production, transportation, and material moving occupations, $0.8 \%$ worked in military specific occupations, and $10.0 \%$ indicated that they worked in some other type of occupation. The majority of the participants worked in private for-profit companies $(66.6 \%) ; 10.6 \%$ worked for private non-profit organizations, $14.7 \%$ worked for the local, state, or federal government, and $8 \%$ were self-employed. The median annual income of these participants was $\$ 44,000(M=\$ 52,962, S D=\$ 43,547)$, and their tenure at their jobs ranged from less than one month to more than 48 years $(M=81.26$ months, $S D=83.58$ months $)$.

\section{Procedure}

The survey research firm contacted panel members with an invitation to participate in a study examining people's experiences at work. Participants were required to be 18 years or older and have full-time employment to be eligible. They were paid \$53 in Study 1 and \$37 in Study 2 
for their participation. Those who missed surveys or terminated their participation early received partial compensation based on the number of surveys they completed. Participants were expected to complete 14 surveys over the course of three months. The initial survey and final survey were largely identical; they assessed participants' demographic characteristics, personality, moral character, and work environment. The 12 weekly surveys assessed participants' emotions, work experiences, and behaviors. It was possible for participants to miss a survey one week, but complete a survey the following week. As such, actual sample sizes varied each week due to some participants failing to complete the weekly survey or indicating that certain questions were not applicable that week. In each weekly survey we had a minimum of 369 participants in Study 1 (mean weekly sample size $=531$ participants $)$, and a minimum of 258 participants in Study 2 $($ mean weekly sample size $=305) .^{3}$

\section{Coworker Survey}

In week 4 of the project, participants were requested to provide an email address of a coworker. The coworkers were sent invitations from the survey research firm indicating that a coworker had recommended them for a study, and as compensation they would receive a giftcard to an online retailer ( $\$ 20$ in Study 1; $\$ 15$ in Study 2). Of the 420 coworkers for whom a valid email address was provided in Study 1, 215 completed the survey (51.2\% response rate). Of the 263 coworkers for whom a valid email address was provided in Study 2, 126 completed the survey (47.9\% response rate). Coworkers knew the targets well $(M=4.19, S D=0.74$; ratings made on a five-point scale anchored by $1=$ not very well and $5=$ extremely well).

\section{Measures}

Both the order of the questionnaires and the order of the items within each questionnaire were randomized for each participant. Each scale is described below, and additional information 
is provided in the supplemental online materials. We calculated test-retest reliability over 13 weeks with data from the 845 participants who completed the initial and final surveys in the WECT Project.

HEXACO-60 inventory (Ashton \& Lee, 2009). Participants were asked to indicate the extent to which they agreed or disagreed with 60 statements about themselves using a five-point scale anchored by $1=$ strongly disagree and $5=$ strongly agree. Each of the six factors was assessed with 10 items. Sample items include: $(\mathrm{H})$ "I wouldn't use flattery to get a raise or promotion at work, even if I thought it would succeed"; (E) "I sometimes can't help worrying about little things"; (X) "I prefer jobs that involve active social interaction to those that involve working alone"; (A) "I rarely hold a grudge, even against people who have badly wronged me." (C) "I often push myself very hard when trying to achieve a goal"; (O) "People have often told me that I have a good imagination." Test-retest reliability over 13 weeks: Honesty-Humility = $.66 ;$ Emotionality $=.75 ;$ Extraversion $=.78 ;$ Agreeableness $=74 ;$ Conscientiousness $=.71$; Openness to Experience $=.83$.

\section{Guilt and Shame Proneness scale (GASP; Cohen, Wolf, Panter, \& Insko, 2011).}

Participants were instructed to imagine themselves in a variety of situations that people could encounter in day-to-day life and indicate the likelihood that they would react in the way described $(1=$ very unlikely, $2=$ unlikely, $3=$ slightly unlikely, $4=$ about $50 \%$ likely, $5=$ slightly likely, $6=$ likely, 7 = very likely). A sample guilt proneness item is: "After realizing you have received too much change at a store, you decide to keep it because the salesclerk doesn't notice. What is the likelihood that you would feel uncomfortable about keeping the money?" A sample guilt-repair orientation item is, "You reveal a friend's secret, though your friend never finds out. What is the likelihood that your failure to keep the secret would lead you to exert extra 
effort to keep secrets in the future?" A sample shame proneness item is, "You successfully exaggerate your damages in a lawsuit. Months later, your lies are discovered and you are charged with perjury. What is the likelihood that you would think you are a despicable human being?" A sample shame-withdrawal orientation item is, "After making a big mistake on an important project at work in which people were depending on you, your boss criticizes you in front of your coworkers. What is the likelihood that you would feign sickness and leave work?" Test-retest reliability over 13 weeks: guilt proneness $=.67$; guilt-repair orientation $=.58$; shame proneness $=$ .58 ; shame-withdrawal orientation $=.56$.

Interpersonal Reactivity Index (IRI; Davis, 1983). Participants were asked to indicate how well each item described them using a five-point scale anchored by $1=$ does not describe me well and $5=$ describes me very well. A sample empathic concern item is, "I often have tender, concerned feelings for people less fortunate than me." A sample perspective taking item is, "I try to look at everybody's side of a disagreement before I make a decision." Test-retest reliability over 13 weeks: empathic concern $=.68$; perspective taking $=.64$.

Self-Importance of Moral Identity scale (Aquino \& Reed, 2002). Participants were presented with a list of moral adjectives and asked to imagine how a person with these characteristics would think, feel, and act. The adjectives were: caring, compassionate, fair, friendly, generous, helpful, hardworking, honest, and kind. They were then asked to indicate the extent to which they agreed or disagreed with five statements about internalization and five questions about symbolization using a seven-point scale anchored by $1=$ strongly disagree and 7 = strongly agree. A sample moral identity-internalization item is, "Being someone who has these characteristics is an important part of who I am." A sample moral identity-symbolization item is, "The types of things I do in my spare time (e.g., hobbies) clearly identify me as having these 
characteristics." Test-retest reliability over 13 weeks: moral identity-internalization = .63; moral identity-symbolization $=.58$.

\section{Consideration of Future Consequences scale (CFC; Strathman, Gleicher, Boninger,}

\& Edwards, 1994). Participants were asked to indicate how characteristic each of 12 statements was of them using a five-point scale anchored by $1=$ extremely uncharacteristic and $5=$ extremely characteristic. A sample item is, "I consider how things might be in the future, and try to influence those things with my day to day behavior." Test-retest reliability over 13 weeks was .59 .

Future Self-Continuity scale (Ersner-Hershfield, Garton, Ballard, Samanez-Larkin, \& Knutson, 2009). Participants were shown seven pairs of circles and were instructed to "Click on the picture that best describes how similar you feel to your future self (in 10 years), in terms of personality, temperament, major likes and dislikes, beliefs, values, ambitions, life goals, ideals, etc." The first pair of circles did not overlap (representing low future-self-continuity), whereas the seventh pair overlapped almost completely (representing high future selfcontinuity). Due to missing data on this item, test-retest reliability was based on 677 participants rather than 845 like the other variables, and it was found to be low, $r=.30$, possibly due to future self-continuity being a single-item scale.

Ethics Position Questionnaire (EPQ; Forsyth, 1980). We measured moral idealism and relativism with the EPQ. Participants were asked to indicate the extent to which they agreed or disagreed with 10 idealism statements and 10 relativism statements using a seven-point scale anchored by $1=$ strongly disagree and $7=$ strongly agree. A sample moral idealism item is, "One should never psychologically or physically harm another person.” A sample moral 
relativism item is, "What is ethical varies from one situation and society to another." Test-retest reliability over 13 weeks: moral idealism $=.57$; moral relativism .59 .

Defining Issues Test (DIT) Short Form (Rest, 1986). We measured cognitive moral development (i.e., moral reasoning ability) with the short form of the DIT, which includes three scenarios and takes approximately 20 minutes to complete. Participants were asked questions about three moral dilemmas, the most classic of which is "Heinz and the Drug." The paragraphlong story describes a European man, Heinz, who is considering stealing an unaffordable cancer drug from a druggist in his town to save his dying wife. Participants are asked what Heinz should do, and then rate and rank 12 issues relevant to the dilemma in terms of their importance. For example, one issue is "Would stealing in such a case bring about more total good for the whole society or not." Another is, "Whether a community's laws are going to be upheld." As recommended by the DIT manual, we used the N2 score in our analyses. Higher N2 scores indicate greater moral reasoning ability (i.e., more advanced cognitive moral development). Testretest reliability could not be calculated for the DIT because it was not included in the final survey due to time constraints.

\section{Exploitiveness-Entitlement (E/E) items from the Narcissism Personality Inventory-}

16 (NPI-16; Ames, Rose, \& Anderson, 2006). We measured the E/E facet of narcissism with five items from the NPI-16 inventory. Participants were presented with five pairs of statements, and instructed to choose the statement in each pair that comes closest to describing their feelings and beliefs about themselves. One sentence in each pair was indicative of E/E. For example, one pair included the statements, "I am more capable than other people," and "There is a lot that I can learn from other people." The former statement reflects E/E. Test-retest reliability over 13 weeks was .59. 
Machiavellianism (MACH) IV Scale (Christie \& Geis, 1970). Participants were asked to indicate the extent to which they agreed or disagreed with 20 statements about themselves using a five-point scale anchored by $1=$ strongly disagree and $5=$ strongly agree. A sample item is, "Never tell anyone the real reason you did something unless it is useful to do so." This scale was not included in Study 1. Test-retest reliability over 13 weeks was $r(303)=.62$.

Brief Self-Control Measure (Tangney, Baumeister, \& Boone, 2004). Participants were presented with 12 statements and asked to indicate how well each statement described them using a five-point scale anchored by $1=$ not at all and $5=$ very much. A sample item is, "I am good at resisting temptation." This scale was not included in Study 1. Test-retest reliability over 13 was $r(303)=.68$.

Work behaviors. Work behaviors were assessed in the weekly surveys and in the coworker survey with the 32-item CWB-Checklist (Spector et al., 2006) and the 20-item OCBChecklist (Fox et al., 2012). The CWB and OCB items were intermixed and presented in a randomized order for each participant. In the self-report version participants were asked to "indicate how often you did each of the following things at your job during the past week" using a five-point scale $(0=$ not at all this week; $1=$ one time this week; $2=$ two times this week; $3=$ three times this week; 4 =four or more times this week). The coworker report was identical except the word "week" was substituted by the word "month" in the instructions and response options. The questionnaire included a "not applicable" response option for each item in case certain behaviors were not relevant to the participant's employment situation. We coded not applicable responses as missing data and used a 10\% threshold for missingness when calculating composite CWB and OCB sum scores. Thus, if participants had missing data on four or more CWB items, or three or more OCB items, they were not given a score on the measure. 


\section{Results}

All individual difference variables were standardized to z-scores for the data analysis for ease of interpretation.

\section{CWB and OCB Correlations}

Both CWB and OCB are counts and not normally distributed. Accordingly, we focused on Kendall's tau-b correlations rather than Pearson correlations. Many of these correlations are significant, but several are not (Table 1). For example, the correlations for Emotionality and cognitive moral development (i.e., moral reasoning ability) were nonsignificant and close to zero.

\section{Latent Profile Analysis (LPA)}

We conducted latent profile analyses (LPA) of the individual difference scale scores to determine which measures best distinguish individuals with low moral character from those with high moral character. LPA—also known as latent class analysis with continuous variables_-is a mixture-model clustering technique that identifies groups of people in a population who have similar responses to a set of measured variables (Flaherty \& Kiff, 2012; Steinley \& Brusco, 2011; Wang \& Hanges, 2011). Individuals in the same latent class are assumed to be similar to others in their class, and different from individuals not in their class. With LPA, one can examine the means and standard errors for each variable in each class to determine which variables best distinguish the members of one class from those in another. These analyses were computed in MPlus 6.11 with MLR (Maximum Likelihood with Robust Standard Errors) estimation (Muthén \& Muthén, 1998-2011).

We examined models with up to six latent classes, and ultimately selected a three-class model by comparing the interpretability and statistical soundness of different models. The three- 
class model, in contrast to four-class and five-class models, had a similar pattern of estimates across both studies. Moreover, it differentiated the latent classes in a more fine-grained way than the two-class model. Thus, we concluded that the three-class model was the best model for our data, and focused on this solution when drawing conclusions about moral character. Figures 1 and 2 contain the results.

Across both studies, empathic concern, moral identity-internalization, guilt proneness, guilt-repair orientation, Conscientiousness, perspective taking, consideration of future consequences, and Honesty-Humility differentiated the high-character class from the lowcharacter class by approximately 1.5 standard deviations (SDs) or more. Machiavellianism and self-control were not assessed in Study 1, but in Study 2 also differentiated the low-character and high-character classes by more than 1.5 SDs. These findings suggest that moral people have a strong capacity for empathy and guilt, value integrity, are conscientious, honest, and considerate of other people's perspectives and the future consequences of their own actions. Moreover, they refrain from manipulating others and are good at resisting temptations.

There were five variables in which the low-character and high-character classes differed by less than one standard deviation across both studies, suggesting that these variables are less relevant to moral character than the others. They were: Emotionality, cognitive moral development, future self-continuity, moral relativism, and moral identity-symbolization. Agreeableness had a difference of less than one standard deviation in Study 1, but the magnitude of the difference was larger in Study 2.

By categorizing individuals into different groups based on their most likely class membership, one can examine the antecedents, consequences, and correlates of class membership. Consistent with prior research on character strengths (Linley et al., 2007), men and 
younger adults were more likely to be classified as low-moral-character than were women and older adults. In Study 1, men comprised $70.6 \%$ of the low-moral-character class, $47.2 \%$ of the average-moral-character class, and $43.8 \%$ of the high-moral-character class, $\chi^{2}(2, N=1020)=$ $44.85, p<.001$. In Study 2, men comprised $63.6 \%$ of the low-moral-character class, $41.9 \%$ of the average-moral-character class, and $36.8 \%$ of the high-moral-character class, $\chi^{2}(2, N=494)=$ $23.70, p<.001$. In Study 1 , the average age was 35.06 years $(S D=10.47)$ in the low-moralcharacter class, $37.78(S D=10.61)$ in the average-moral-character class, and 41.69 years $(S D=$ 11.74) in the high-moral-character class, $F(2,1014)=26.44, p<.001$. In Study 2 , the average age was 36.43 years $(S D=10.94)$ in the low-moral-character class, 42.88 years $(S D=10.33)$ in the average-moral-character class, and 42.88 years $(S D=10.33)$ in the high-moral-character group, $F(2,490)=19.30, p<.001$.

Although not a focus of our research program, the topic of political ideology has received considerable attention in the field of moral psychology (e.g., Graham, Haidt, \& Nosek, 2009; Haidt, 2007). As such, we thought it would be interesting to explore whether political ideology was associated with moral character. An item in the initial survey asked, "Which response best describes your political beliefs?" $(1=$ very liberal, 2 = liberal, $3=$ slightly liberal, $4=$ moderate/middle-of-the-road, $5=$ slightly conservative, $6=$ conservative, $7=$ very conservative; libertarian and other were coded as missing). Overall, our samples were politically moderate and this did not meaningfully differ by moral character classification. Low-moral-character class (Study $1 M=4.12, S D=1.57$; Study $2 M=3.65, S D=1.67$ ); Average-moral-character class (Study $1 M=3.99, S D=1.53$; Study $2 M=4.15, S D=1.72$ ); High-moral-character class (Study $1 M=4.05, S D=1.73$; Study $2 M=3.98, S D=1.66)$. As indicated by these means, in Study 1 , the average moral character group was slightly more liberal than the low and the high moral 
character groups, whereas in Study 2 the average moral character was slightly more conservative than the low and high moral character groups. Thus, we did not see a consistent pattern across the studies, and the observed differences in ideology were minimal.

\section{CWB and OCB Regression Analyses}

It is clear that the classes identified in the LPA models differ, but is it appropriate to label some people "low-moral-character" and others "high-moral-character" on the basis of these results? That is, do the differences in classifications indicate that one class of respondents (i.e., the high-moral-character class) is more moral than another (i.e., the low-moral-character class)? Answering this question requires criterion measures. If, as we suggest by our labels, the latent classes are indicative of moral character, then we should observe corresponding differences in the amount of unethical behavior and ethical behavior committed by employees classified into these groups. To this end, we conducted regression analyses testing whether the three moral character classifications predicted self-reported work behaviors and coworker reported work behaviors. The average-moral-character group (the largest category) was selected as the reference group. Thus, the regression models tell us how the behavior of employees classified as low in moral character and high in moral character, respectively, compares to the behavior of employees classified as average in moral character.

We analyzed the coworker reports of CWB and OCB with negative binomial regressions, computed in MPlus 6.11 with MLR estimation (Muthén \& Muthén, 1998-2011). We analyzed the weekly self-reports with multilevel models in HLM 7 with Overdispersed Poisson distribution and robust standard errors (Raudenbush, Bryk, \& Congdon, 1996-2011). The multilevel models included fixed (level 2) effects for all independent variables, a random (level 
1) intercept parameter to account for the nesting of observations within persons, and a fixed (level 1) effect for week number to account for changes in CWB and OCB over time.

As predicted, low-moral-character employees committed more CWB and less OCB than high-moral-character employees (Figure 3). Regression models that included demographic and organizational controls established the robustness of the results (Tables 2 and 3). The results of the CWB multilevel models (the first two columns in Table 2) are particularly striking because they demonstrate that employees with a low-moral-character classification reported more CWB than employees with an average or high-moral-character classification over a three-month time span, controlling for a host of demographic and organizational characteristics.

For self-reported OCB (the last two columns in Table 2), the low-moral character contrast was nonsignificant in both studies; the high-moral-character contrast was significant in Study 2, and although in the same direction in Study 1, it was nonsignificant $(p=.17)$. Nonetheless, although the moral character results were not as strong for self-reported OCB as self-reported $\mathrm{CWB}$, the pattern in both studies is such that those with a high-moral-character classification engaged in more OCB than employees with average or low-moral-character classifications (Figure 3). Contrary to expectations, the low-moral-character employees did not report fewer OCB acts than the average-moral-character employees - the low-moral-character and averagemoral-character classes reported nearly identical levels of OCB.

Consistent with the notion that CWB is generally private, the coworkers observed less CWB than the participants self-reported. This pattern is particularly interesting because the selfreport survey asked employees about their behavior during the past week, whereas the coworker survey asked about the employees' behaviors during past month. Thus, Figure 3 shows that lowmoral-character employees self-reported more CWB acts in the first week of the study than their 
coworkers observed during an entire month. The same pattern was not true for OCB, which makes sense given that employees are generally motived to make their OCB public and their CWB private.

Despite the private nature of CWB, the low-moral-character contrast predicted coworkers' observations of CWB in both studies (Table 3), although the effect was marginal in Study 1 ( $p=.07)$. Employees classified as low in moral character committed more acts of CWB than employees classified as average in moral character, as reported by their coworkers. The high-moral-character contrast did not predict coworkers' observations of CWB in either study (Table 3), as there were few incidents of CWB observed by coworkers of employees with high or average moral character (see Figure 3).

The high-moral-character contrast significantly predicted coworkers' observations of OCB in both studies. Employees classified as high in moral character committed more acts of OCB than employees classified as average in moral character, as reported by their coworkers. The low-moral-character contrast was significant in Study 1, but not in Study $2(p=.52)$ One interpretation of these results is that it is not necessarily unethical to abstain from OCB, but employees who are particularly moral do more of these helpful behaviors than do those of low or average character.

\section{Discussion}

What are the characteristics of moral people? Our results indicate that they are considerate of others, good at self-regulation, and value being moral. Specifically, they consider other people's perspectives and feelings (high perspective taking \& empathic concern) and refrain from manipulating others (low Machiavellianism). Moreover, when they do something wrong, they feel guilty about their behavior and change their future behavior accordingly (high 
guilt proneness and guilt-repair orientation). In general, they can be described as sincere, modest, and fair (high Honesty-Humility), as well as disciplined, prudent, and organized (high Conscientiousness). In addition, they are good at resisting temptations (high self-control) and think about future consequences of their behavior (high consideration of future consequences). Finally, integrity is important to them and they want to see themselves as possessing moral traits (high moral-identity-internalization).

Two of the more surprising results were that cognitive moral development (i.e., moral reasoning ability) and Emotionality were not found to be critical elements of character, findings we discuss further in the General Discussion. It was also surprising that none of the demographic or organizational variables that were included in the regression models had consistent effects on CWB or OCB. Prior research implies that the enforcement of an ethics code and income should have predicted unethical behavior (Kish-Gephart et al., 2010; Piff, Stancato, Côté, MendozaDenton, \& Keltner, 2012; Treviño et al., 2014). However, neither these variables, nor the other demographic and organizational controls, showed consistent effects in the two studies. Age was the only control variable to have a significant effect on self-reported CWB in both studies-older people self-reported less CWB than younger people—but this relationship was nonsignificant in the coworker models. Being a supervisor (operationalized as having at least one direct report versus no direct reports) had significant effects on self-reported OCB in both studiessupervisors reported more OCB than non-supervisors-but this relationship was nonsignificant in the coworker models. In the coworker models, none of the control variables had significant effects in both studies (except Asian versus White, which had significant effects on CWB in both studies, but in opposite directions). In sum, the lack of robust results for the control variables suggest that moral character traits predict ethical and unethical workplace behaviors better than 
basic organizational and demographic characteristics. We discuss this issue further in the General Discussion.

\section{Study 3}

Study 3 builds on the previous studies by investigating three scales that were not available at the time Studies 1 and 2 were designed: a new measure of moral disengagement by Moore and colleagues (Moore, Detert, Klebe Treviño, Baker, \& Mayer, 2012), a new measure of social value orientation by Murphy and colleagues (Murphy, Ackermann, \& Handgraaf, 2011), and a new measure of moral foundations by Graham and colleagues (Graham et al., 2011). In addition to these scales, a revised guilt proneness scale was investigated in Study 3 (Cohen, Kim, Jordan, \& Panter, 2014), as was the complete NPI-16 measure of narcissism (Ames et al., 2006), given that only the E/E component was measured in the previous studies. To replicate our key findings from Studies 1 and 2, the survey also included: the HEXACO-60 personality inventory, moral identity-internalization items, consideration of future consequences scale, brief selfcontrol measure, and Machiavellianism IV scale. ${ }^{4}$

Two new criterion variables were tested in Study 3-delinquency and approval of unethical negotiations behaviors - both of which have been used as criterion variables in prior research on unethical behavior (Ashton \& Lee, 2008b; Cohen et al., 2011; Hershfield, Cohen, \& Thompson, 2012). Examining the relationship between moral character and these constructs allows us to broaden our scope beyond CWB and OCB to other indicators of unethicality. 


\section{Method}

\section{Participants \& Procedure}

In August 2013, a private survey research firm was contracted to conduct a 45-minute survey of American adults, about "personality and social behavior." Participants were recruited via a different subcontractor than in the prior studies to ensure Study 3 was completed by new participants. To be eligible, participants were required to be 18 years or older. They were paid $\$ 2.75$ from the research firm as appreciation for their participation.

Data were collected from 665 participants, of whom 553 finished the survey. Participants could skip questions, so our sample size varies somewhat across the different analyses, as we used all available data rather than just those with no missing responses. Breaks were permitted and answers were saved automatically as respondents progressed through the survey. The order of measures and the items within each measure were randomized to minimize issues related to attrition and missing data. All variables were standardized to z-scores for the data analysis for ease of interpretation.

Participants lived in 48 U.S. states. The sample was 53.5\% women. Ages ranged from 18 to 91 years $(M=55.64$ years, $S D=15.31$; the average age was approximately 15 years older than in Studies 1 and 2). The sample contained White (72.0\%), Black (11.5\%), Hispanic (5.6\%), Asian $(2.1 \%)$, and multiracial or other $(8.7 \%)$ participants, which roughly corresponds to U.S. census data (http://www.census.gov/prod/cen2010/briefs/c2010br-02.pdf). In regards to education, $43.0 \%$ had a Bachelor's degree or more, whereas $57.0 \%$ had less education than a Bachelor's degree. Unlike Studies 1 and 2, which assessed income with an open-ended item where respondents were asked to type their annual salary into a text box, Study 3 asked respondents to select one of nine ordinal categories ranging in $\$ 25,000$ units from $1=\$ 0$ to 
$\$ 25,000$ to $9=\$ 200,001$ or more. The median income of the sample was between $\$ 25,000$ and $\$ 50,000$.

\section{Measures}

The HEXACO factors, empathic concern, perspective taking, moral identityinternalization, consideration of future consequences, self-control, and Machiavellianism were measured with the same items used in Studies 1 and 2. The new and revised measures included in Study 3 are described below. Tables in the supplemental online materials report descriptive statistics, alpha coefficients, and correlations among the variables.

\section{Moral Disengagement (Moore, Detert, Kleve, Treviño, Baker, \& Mayer, 2012).}

Participants were presented with eight statements, and were asked to indicate the extent to which they agreed or disagreed with each statement on a seven-point scale, ranging from $1=$ strongly disagree to 7 = strongly agree. Sample items include: "Some people have to be treated roughly because they lack feelings that can be hurt" and "Taking something without the owner's permission is okay as long as you're just borrowing it."

\section{Social Value Orientation (SVO; Murphy, Ackermann, \& Handgraaf, 2011). In six} items, participants allocated a hypothetical pool of resources between themselves and another person. Each item had nine allocation choices, and participants were instructed as follows: In this task we ask you to imagine that you have been randomly paired with another person, whom we will refer to simply as the "Other." This other person is someone you do not know. Your choices will produce points for both yourself and the "Other" person. The more points you receive, the better for you, and the more points the "Other" receives, the better for him/her. For each of the six situations, please select a letter from the dropdown menu to indicate the column you prefer the most. 
When this measure is scored (via a somewhat complicated method described in Murphy et al., 2011), it results in a continuous ratio score that indicates how much a respondent benefits oneself versus the other person. The lowest range of scores represents a competitive orientation, the next range of scores represents an individualistic orientation, followed by a prosocial orientation, and finally the highest range represents an altruistic orientation.

\section{Moral Foundations Questionnaire (MFQ; Graham, Nosek, Haidt, Iyer, Koleva, \&}

Ditto, 2011). Five moral values (i.e., foundations) were measured with the MFQ: Harm/Care, Fairness/Reciprocity, Ingroup/Loyalty, Authority/Respect, and Purity/Sanctity. Participants were presented with 30 items divided across two sections.

In section one, participants were asked, "When you decide whether something is right or wrong, to what extent are the following considerations relevant to your thinking? [0] = not at all relevant (This consideration has nothing to do with my judgments of right and wrong); [1] = not very relevant; [2] = slightly relevant; [3] = somewhat relevant; $[4]=$ very relevant; $[5]=$ extremely relevant (This is one of the most important factors when I judge right and wrong)." Sample items in this section include: "Whether or not someone suffered emotionally" (Harm/Care): "Whether or not some people were treated differently than others" (Fairness/Reciprocity); "Whether or not someone's action showed love for his or her country" (Ingroup/Loyalty); "Whether or not someone showed a lack of respect for authority"; (Authority/Respect); "Whether or not someone violated standards of purity and decency" (Purity/Sanctity).

In section two, participants indicated their agreement with 15 statements (Strongly disagree $=0$, Moderately disagree $=1$, Slightly disagree $=2$, Slightly agree $=3$, Moderately agree $=4$, Strongly agree $=5$ ). Sample items in this section include: "Compassion for those who 
are suffering is the most crucial virtue" (Harm/Care); "Justice is the most important requirement for a society" (Fairness/Justice); "People should be loyal to their family members, even when they have done something wrong" (Ingroup/Loyalty); "Respect for authority is something all children need to learn" (Authority/Respect); "People should not do things that are disgusting, even if no one is harmed" (Purity/Sanctity).

Narcissism Personality Inventory-16 (NPI-16; Ames et al., 2006). Whereas Studies 1 and 2 only included the five exploitiveness/entitlement items from the NPI-16, Study 3 included the full measure. Participants were presented with 16 pairs of statements, and instructed to choose the statement in each pair that comes closest to describing their feelings and beliefs about themselves. For example, one pair included the statements, “Being an authority doesn't mean that much to me," and "People always seem to recognize my authority." The latter statement reflects narcissism.

\section{Five-Item Guilt Proneness Scale and Guilt-Repair Orientation items (Cohen et al.,}

2011, 2014). In Study 3, we measured guilt proneness with the newly-developed five-item guilt proneness scale (GP-5; Cohen et al., 2014), which is a modification of the guilt proneness subscale from the GASP (Cohen et al., 2011). The GP-5 has a five-point rating scale $(1=$ Extremely Unlikely, 2 = Unlikely, $3=$ About 50\% Likely, $4=$ Likely, $5=$ Extremely Likely), and an additional item. ${ }^{5}$ These modifications give the GP-5 better psychometric properties and item functioning than the GASP subscale (Cohen et al., 2014). The guilt-repair orientation items from the GASP are not part of the GP-5, but in light of the results from Studies 1 and 2, we included these four items in Study 3, randomly interspersed with the GP-5 items.

Delinquency (Ashton \& Lee, 2008). Participants self-reported six kinds of delinquent behavior, including forms of cheating, vandalism, smuggling, and stealing. Each delinquency 
item had eight response options, with different frequency ranges for each item. Sample items include, "What is the approximate total dollar value of all items that you have stolen?" and "During high school and/or college, on what percentage of your exams and assignments did you cheat, for your own benefit or for that of other students?" After standardizing the responses (because each item had different response options), the six items were averaged to form a delinquency composite. Positive delinquency scores indicate more delinquency than the average participant in the sample and negative delinquency scores indicate less delinquency than the average participant in the sample.

\section{Approval of Unethical Negotiation Behaviors (Lewicki, Saunders, \& Barry, 2007).}

We measured approval of unethical negotiation behaviors with the Self-reported Inappropriate Negotiation Strategies (SINS II) scale created by Lewicki, Saunders, and Barry (2007). In the SINS II scale, participants indicate whether they endorse lies, bribes, and other unethical negotiation tactics as appropriate techniques. Specifically, participants were presented with descriptions of a variety of negotiation behaviors and were asked to rate the inappropriateness versus appropriateness of these behaviors, using a seven-point scale $(1=$ very inappropriate, 2 = inappropriate, 3 = slightly inappropriate, $4=$ neutral, $5=$ slightly appropriate, $6=$ appropriate, $7=$ very appropriate . A sample item is, "Intentionally misrepresent information to your opponent in order to strengthen your negotiating arguments or position."

Although the full 25-item SINS II scale was administered, only 13 items in the scale are considered unethical by most people (Cohen, 2010; Cohen et al., 2011; Hershfield et al., 2012; Lewicki et al., 2007). These are the items assessing: attacking an opponent's network (e.g., attempting to get your opponent fired); false promises (e.g., promising concessions that you will 
not provide); misrepresentation (e.g., misrepresenting information to your opponent); and inappropriate information gathering (e.g., bribing people to get information about your opponent). Our criterion measure, approval of unethical negotiation behaviors, is a mean composite score of the ratings of the 13 items from these subscales, consistent with how this measure has been used in prior research on unethical choices (e.g., Hershfield et al., 2012).

\section{Results}

First, we examined the correlations of each variable with the criterion variables (Table 4), and then we conducted a latent profile analysis to determine which variables best distinguish individuals with low moral character from those with high moral character (Figure 4; see also supplemental online materials). The variables that distinguished the low moral character and high moral character classes in the prior studies also distinguished these classes in Study 3 . There is, of course, some variability across the studies in the relative importance of each variable given that each study contained a different set of variables. Nonetheless, Study 3 replicates Studies 1 and 2 by highlighting the importance of guilt proneness, guilt-repair orientation, empathic concern, moral identity-internalization, and low Machiavellianism for determining moral character, all of which differentiated the low class from the high-class by more than 1.5 standard deviations and correlated significantly with the criterion measures. Perspective taking, consideration of future consequences, and self-control showed, in general, the expected patterns of results in that they differentiated the groups and correlated with the criterion variables, but the results for these variables were somewhat weaker than the others. For example, consideration of future consequences was uncorrelated with delinquency. Although narcissism did not differentiate the groups very well in the LPA, it did significantly correlate with both criterion measures in the expected direction. 
Conscientiousness and Honesty-Humility again emerged as the two HEXACO dimensions with the strongest relationship to moral character. These broad personality factors distinguished the low-moral-character class from the high-moral-character class by more than 1.3 standard deviations, and were significantly correlated with the criterion variables. As before, Emotionality did not distinguish the classes very well and was only weakly correlated with the criterion measures.

In regards to the newly-added variables, moral disengagement was particularly important, as was the Harm/Care and Fairness/Justice moral foundations. Both these variables distinguished the low and high classes by more than 1.5 standard deviations and correlated significantly with both criterion variables. The other moral foundations also distinguished the low and high moral character classes and correlated with the criterion variables, but the results for the Ingroup/Loyalty, Authority/Respect, and Purity/Sanctity were relatively weaker than the Harm/Care and Fairness/Justice foundations.

Surprisingly, social value orientation did not differentiate the classes well and was only weakly correlated with the criterion measures. This suggests that SVO is not as diagnostic of moral character as compared to the other individual differences we investigated.

As in the prior studies, men and younger adults were significantly more likely to be classified as low character than were women and older adults. Specifically, men comprised $60.6 \%$ of the low-moral-character class, $45.5 \%$ of the average-moral-character class, and $42.1 \%$ of the high-moral-character class, $\chi^{2}(2, N=602)=9.54, p=.008$. The average age was 49.59 years $(S D=18.00)$ for the low-moral-character class, 55.06 years $(S D=15.51)$ for the averagemoral-character class, and 58.65 years $(S D=13.08)$ for the high-moral-character class, $F(2,596)$ $=12.50, p<.001$. As in Studies 1 and 2, respondents were politically moderate and ideology was 
unrelated to moral character, $F(2,580)=1.11, p=.33)$ : low-moral-character class $(M=4.10, S D$ $=1.90)$; average-moral-character class $(M=4.12, S D=1.77)$; high-moral-character class $(M=$ 4.34, $S D=1.78)$.

Figure 5 displays the differences in delinquent behaviors and judgments of unethical negotiation tactics by moral character classification. Regression models tested whether the classifications predicted these criterion variables while controlling for demographic characteristics (Table 5). As expected, low-moral-character respondents reported significantly more delinquent behavior and judged unethical negotiation tactics to be significantly less inappropriate as compared to average-moral-character respondents. High-moral-character respondents did the reverse - they reported marginally less delinquent behavior and judged unethical negotiation behaviors as significantly more inappropriate as compared to averagemoral-character respondents.

\section{Discussion}

Guilt proneness, guilt-repair orientation, empathic concern, moral identity-internalization, low Machiavellianism, low moral disengagement, and strong Harm/Care and Fairness/Justice moral foundations all appear to be important elements of moral character. Perspective taking, consideration of future consequences, self-control, and the other three moral foundations also appear to be diagnostic of moral character, but possibly relatively less so than the other variables

included in Study 3. Importantly, we replicated Studies 1 and 2 by showing that of the six major personality dimensions, the Emotionality dimension is the least indicative of moral character, whereas the Honesty-Humility and Conscientiousness dimensions are the most indicative. Surprisingly, social value orientation was not found to be a key element of moral character, despite prior research indicating that it influences charitable giving (Van Lange, Bekkers, 
Schuyt, \& Van Vugt, 2007) and cooperative behavior in social dilemmas (Bailliet, Parks, \& Joireman, 2009).

As in the first two studies, women and older adults were found to have higher levels of moral character than men and younger adults, respectively. And, although gender and age did not significantly predict delinquent behavior in the regression model with moral character, they did each predict judgments of unethical negotiation strategies. These results suggest a tendency for women to be more ethical than men, and for older adults to be more ethical than younger adults. However, the influence of these demographic characteristics on actual behavior appears to be weak and less consistent than the influence of moral character traits on behavior.

Income was unrelated to delinquency and approval of unethical negotiation tactics, just as it was unrelated to CWB. The null results for income in each of our three studies call into question the generalizability of prior studies linking higher social class to unethical behavior (cf. Piff et al., 2012; Trautmann, de Kuilen, \& Zeckhauser, 2013). The current studies indicate that social class is not associated with unethical behavior if social class is operationalized as one's income. However, if social class is operationalized in a different manner, it may indeed be associated with delinquency, CWB, and other unethical behaviors. Such a conclusion, however, awaits further research that compares different instantiations of social class.

\section{General Discussion}

We identified distinguishing features of adults low versus high in moral character, and demonstrated that employees classified as low in moral character committed harmful work behaviors more frequently and helpful work behaviors less frequently than employees classified as high in moral character, according to their own admissions and their coworkers' observations (Study 1 and Study 2). Moreover, low-moral-character adults reported engaging in more 
delinquent behavior and had more lenient attitudes toward unethical negotiation tactics as compared to high-moral-character adults (Study 3). We conclude from these results that people with strong moral character can be identified by self-reports in surveys, and these self-reports predict consequential work behaviors months after the initial assessment. An important area for future work is to investigate whether the questionnaires we administered in our studies can be used in applied settings in which individuals are identifiable and motivated to make a positive impression. Future studies are also needed to determine which of the moral character traits we identified are necessary and sufficient to predict harmful and helpful behaviors in applied settings.

By showing robust relationships between individual differences and behaviors, controlling for a host of demographic and organizational characteristics, our research disputes situationist arguments that question the importance of personality for behavioral prediction (cf. Bazerman \& Gino, 2012; Davis-Blake \& Pfeffer, 1989; Doris, 2002; Mischel, 1968; Ross \& Nisbett, 1991; Zimbardo, 2004). These results suggest that moral character traits predict harmful and helpful work behaviors more strongly and robustly than do basic organizational and demographic variables - a conclusion that is consistent with prior work on the power of personality to predict consequential behaviors and life outcomes (Funder \& Ozer, 1983; Ozer \& Benet-Martínez, 2006; Roberts, Kuncel, Shiner, Caspi, \& Goldberg, 2007).

Of course, the current studies were not designed to compare the effect sizes or explore the complex interrelationships among individual difference variables and situational variables, so we can only speculate on their relative importance (cf. Aquino et al., 2009; Funder \& Ozer, 1983; Kurtines, 1986). Moreover, despite the long history of the person versus situation debate (Fleeson \& Noftle, 2008), we view the dichotomy between the two to be largely a false one in 
that personality influences situations and vice versa. For example, we know from prior research (Meier \& Spector, 2013), as well as our own data (Kim, Cohen, \& Panter, 2014), that there is a reciprocal relationship between work stressors (e.g., organizational constraints, interpersonal conflict at work) and CWB such that increases in CWB lead to increases in work stressors and vice versa. Coupled with the current findings, this suggests the interesting prediction that bad work environments are not uniformly faced by low- and high-moral-character employees. Rather we theorize that low-moral-character employees experience a disproportionate amount of work stressors owing to their own bad behavior, making the relationship between personality, situations, and behavior a dynamic one.

We assume that in the moral domain, similar to other domains, there are "strong situations" where personality matters very little for behavioral prediction, as well as "weak situations" where personality matters a lot for behavioral prediction. Likewise, we assume that there are "strong moral character traits" and "weak moral character traits," with the former predicting behavior strongly and consistently across a variety of situations, and the latter predicting behavior weakly and inconsistently across different situations. The variables we identified as relatively important indicators of moral character (e.g., guilt proneness, empathic concern, moral identity internalization) are likely to be strong moral character traits, whereas those that we deemed relatively less important (e.g., moral idealism, moral relativism, Agreeableness) are likely to be weak moral character traits.

Given the longstanding debate about the relative importance of reasoning versus emotion in determining people's moral judgments (Greene, 2013; Greene et al., 2001; Haidt, 2001, 2010; Narvaez, 2010), we find it interesting that neither moral reasoning ability (i.e., cognitive moral development) nor the broad Emotionality factor of personality were strong determinants of moral 
character. Although prior research suggests that moral reasoning ability predicts unethical choices at work (Kish-Gephart et al., 2010), our results suggest that this construct is not a central component of moral character, or at least not as relevant as the other constructs measured in our studies. We suspect that moral reasoning ability is important for determining choices in difficult dilemmas involving multiple moral considerations. Whistleblowing is an example of a challenging moral dilemma that employees might face, where loyalty and fairness values are in conflict (Waytz, Dungan, \& Young, 2013). Whistleblowing and other difficult moral decisions are rare in organizations compared to the behaviors we investigated in our studies. Thus, our conclusion is that moral reasoning ability is relatively inconsequential for determining moral and immoral work behavior in everyday situations where what is right and what is wrong is largely unambiguous.

Regarding Emotionality, our results corroborate prior HEXACO studies by showing that Honesty-Humility and Conscientiousness are more relevant to moral character than are the other four broad personality dimensions (e.g., Marcus et al., 2007). However, this conclusion is at odds with studies using Big Five personality scales, which highlight the importance of Agreeableness and Emotional Stability (as well as Conscientiousness) for predicting CWB and other deviant behaviors (e.g., Berry et al., 2012; Berry et al., 2007; Henle \& Gross, 2013). It is important to recognize that the HEXACO dimensions of Emotionality and Agreeableness are rotational variants of the Big Five dimensions of Emotional Stability and Agreeableness (Ashton \& Lee, 2007; Ashton et al., 2014). Thus, despite the fact that the labels used to describe these dimensions are quite similar, they nonetheless capture different facets of personality. Unlike the Emotional Stability dimension in the Big Five, the Emotionality dimension in the HEXACO does not include anger, but does include sentimentality, which is part of the Agreeableness factor 
in Big Five frameworks. In the HEXACO, the Agreeableness factor "excludes sentimentality and includes (lack of) anger" making it "perhaps even more consistent with the name Agreeableness" (Ashton \& Lee, 2007, p. 152).

Although the relationship between Agreeableness and moral character was relatively weak in Study 1, it was moderate in Studies 2 and 3, and the correlations of Agreeableness with CWB and OCB were significant for both self-reports and coworkers' observations. This suggests that although not a critical component, Agreeableness is at least somewhat diagnostic of moral character, likely because to some extent it captures consideration of others, much like empathic concern and perspective taking. In contrast, Emotionality, unlike the other five HEXACO scales, was uncorrelated with CWB and OCB, and only weakly correlated with delinquency and approval of unethical negotiation behaviors. Of the all 22 individual differences that we measured in Studies 1 and 2, Emotionality had the weakest relationship with moral character across the different statistical analyses we conducted (see supplemental online materials). Thus, our results are clear in indicating that that the broad personality dimension of Emotionality is inconsequential for determining character.

By arguing that moral reasoning ability and Emotionality are relatively uninformative for understanding moral character, we are not making a general claim that cognitive and emotional processes are irrelevant. Indeed, empathic concern and guilt proneness are emotional traits, and were found to be very diagnostic of character. Similarly, perspective taking and consideration of future consequences are cognitive traits, and they too were found to be very diagnostic of character. Thus, our conclusion is that emotions and cognitions are both important for understanding character, but not every emotional trait is important nor is every cognitive trait. 


\section{Conclusion}

Moral character is a multifaceted construct encompassing a variety of individual differences, including traits related to consideration of others, self-regulation, and moral identity. Many of the individual differences we identified as diagnostic of character indicate a disposition toward considering the needs and interests of others and how one's own actions affect other people (e.g., Honesty-Humility, empathic concern, perspective taking, guilt proneness, guiltrepair orientation, low Machiavellianism, low moral disengagement). We conjecture that these traits reflect the motivational element of moral character - the desire to do good and avoid doing bad. Other individual differences we identified as diagnostic of moral character indicate a disposition toward regulating one's behavior effectively, specifically with reference to actions that have positive short-term consequences but negative long-term consequences for one's self or others (e.g., Conscientiousness, self-control, consideration of future consequences). We conjecture that these traits reflect the ability element of moral character - the capacity to do good and avoid doing bad. Finally, moral identity seems to be a third element of moral character. It is related to the motivational and ability elements in that an individual could feel that it is important to be the kind of person who considers others interests' rather than exclusively one's own, and/or feel it is important to be the kind of person who has self-discipline. Either of these concerns could contribute to a highly internalized identity as a moral person. By identifying character traits related to the consideration of others, self-regulation, and moral identity, our findings are reminiscent of Robert Hogan's earlier work on morality emphasizing the importance of empathy, socialization, and autonomy (Hogan, 1973, 1975).

We hope this research prompts future theoretical and empirical inquiries aimed at developing an organizing framework for understanding character and its relation to 
consequential life outcomes. To more fully map the landscape, we encourage future studies that investigate the interrelationships and latent structure of the traits we identified as diagnostic of character in the current studies. Researchers could use multidimensional scaling (Borg, Groenen, \& Mair, 2013), bifactor models (Reise, Moore, \& Haviland, 2010), and other advanced statistical techniques to uncover the structure of character. Such analyses are beyond the scope of the current research, but are critical for fully understanding what makes a person help others and refrain from harming others. 


\section{References}

Allport, G. W. (1937). Personality: A psychological interpretation. New York: Henry Holt \& Company.

Ames, D. R., Rose, P., \& Anderson, C. P. (2006). The NPI-16 as a short measure of narcissism. Journal of Research in Personality, 40, 440-450.

Aquino, K., Freeman, D., Reed, A., G, K., \& Felps, W. (2009). Testing a social-cognitive model of moral behavior: The interactive influence of situations and moral identity centrality. Journal of Personality and Social Psychology, 97(1), 123-141. doi: 10.1037/a0015406

Aquino, K., \& Reed, A. (2002). The self-importance of moral identity. Journal of Personality and Social Psychology, 83(6), 1423-1440.

Ashton, M. C., \& Lee, K. (2007). Empirical, theoretical, and practical advantages of the HEXACO model of personality structure. Personality and Social Psychology Review, 11(2), 150-166. doi: 10.1177/1088868306294907

Ashton, M. C., \& Lee, K. (2008a). The HEXACO model of personality structure and the importance of the H Factor. Social and Personality Psychology Compass, 2, 1952-1962. doi: 10.1111/j.1751-9004.2008.00134.x

Ashton, M. C., \& Lee, K. (2008b). The prediction of Honesty-Humility-related criteria by the HEXACO and Five-Factor Models of personality. Journal of Research in Personality, 42(5), 1216-1228. doi: 10.1016/j.jrp.2008.03.006

Ashton, M. C., \& Lee, K. (2009). The HEXACO-60: A short measure of the major dimensions of personality. Journal of ersonality Assessment, 91(4), 340-345. doi: 
$10.1080 / 00223890902935878$

Ashton, M. C., Lee, K., \& Vries, R. E. d. (2014). The HEXACO Honesty-Humility, Agreeableness, and Emotionality Factors A Review of Research and Theory. Personality and Social Psychology Review. doi: 10.1177/1088868314523838

Balliet, D., Parks, C., \& Joireman, J. (2009). Social value orientation and cooperation in social dilemmas: A meta-analysis. Group Processes \& Intergroup Relations, 12(4), 533-547. doi: $10.1177 / 1368430209105040$

Bandura, A. (1986). Social foundations of thought and action. Englewood Cliffs, NJ.

Batson, C. D., Lishner, D. A., Carpenter, A., Dulin, L., Harjusola-Webb, S., Stocks, E., . . . Sampat, B. (2003). "...As you would have them do unto you": Does imagining yourself in the other's place stimulate moral action. Personality and Social Psychology Bulletin, 29(9), 1190-1201. doi: http://dx.doi.org/10.1177/0146167203254600

Baumeister, R. F., Vohs, K. D., \& Tice, D. M. (2007). The Strength Model of SelfControl.Current Directions in Psychological Science, 16(6), 351-355. doi:10.1111/j.1467-8721.2007.00534.x

Bazerman, M. H., \& Gino, F. (2012). Behavioral Ethics: Toward a Deeper Understanding of Moral Judgment and Dishonesty. Annual Review of Law and Social Science, 8(1), 85104. doi: 10.1146/annurev-lawsocsci-102811-173815

Berry, C. M., Carpenter, N. C., \& Barratt, C. L. (2012). Do other-reports of counterproductive work behavior provide an incremental contribution over self-reports? A meta-analytic comparison. Journal of Applied Psychology, 97(3), 613-636. doi: 10.1037/a0026739

Berry, C. M., Ones, D. S., \& Sackett, P. R. (2007). Interpersonal deviance, organizational 
deviance, and their common correlates: A review and meta-analysis. Journal of Applied Psychology, 92(2), 410-424.

Borg, Ingwer, Groenen, Patrick J. F., \& Mair, Patrick. (2013). Applied multidimensional scaling. Springer.

Bourdage, J. S., Lee, K., Lee, J.-H., \& Shin, K.-H. (2012). Motives for organizational citizenship behavior: Personality correlates and coworker ratings of OCB. Human Performance, 25(3), 179-200. doi: 10.1080/08959285.2012.683904

Brief, A. P. (2012). The good, the bad, and the ugly: What behavioral business ethics researchers ought to be studying. In D. De Cremer \& A. E. Tenbrunsel (Eds.), Behavioral Business Ethics: Shaping an Emerging Field. New York: Routledge.

Christie, R., \& Geis, F. L. (1970). Studies in Machiavellianism. New York: Academic Press.

Cohen, T. R. (2010). Moral emotions \& unethical bargaining: The differential effects of empathy and perspective taking in deterring deceitful negotiation. Journal of Business Ethics, 94, 569-579. doi: 10.1007/s10551-009-0338-Z

Cohen, T. R., Kim, Y., Jordan, K. P. \& Panter, A. T. (2014). Measuring guilt proneness in applied settings with the five-item guilt proneness scale (GP-5). Manuscript submitted for publication.

Cohen, T. R., Panter, A. T., \& Turan, N. (2012). Guilt proneness and moral character. Current Directions in Psychological Science, 21(5), 355-359. doi: 10.1177/0963721412454874

Cohen, T. R., Panter, A. T., \& Turan, N. (2013). Predicting counterproductive work behavior from guilt proneness. Journal of Business Ethics, 114, 45-53. doi: 10.1007/s10551-012$1326-2$ 
Cohen, T. R., Panter, A. T., Turan, N., Morse, L., \& Kim, Y. (2013). Agreement and similarity in self-other perceptions of moral character. Journal of Research in Personality. 47, 816830. doi: 10.1016/j.jrp.2013.08.009

Cohen, T. R., Wolf, S. T., Panter, A. T., \& Insko, C. A. (2011). Introducing the GASP scale: A new measure of guilt and shame proneness. Journal of Personality and Social Psychology, 100(5), 947-966. doi: 10.1037/a0022641

Davis, M. H. (1983). Measuring individual differences in empathy: Evidence for a multidimensional approach. Journal of Personality and Social Psychology, 44(1), 113126.

Davis-Blake, A., \& Pfeffer, J. (1989). Just a mirage: The search for dispositional effects in organizational research. Academy of Management Review, 14(3), 385-400. doi: 10.5465/AMR.1989.4279071

Doris, J. M. (2002). Lack of character: Personality and moral behavior. Cambridge: Cambridge University Press.

Eisenberg, N. (2000). Emotion, regulation, and moral development. Annual Review of Psychology, 51, 665-697.

Ersner-Hershfield, H., Garton, M. T., Ballard, K., Samanez-Larkin, G. R., \& Knutson, B. (2009). Don't stop thinking about tomorrow: Individual differences in future self-continuity account for saving. Judgment and Decision Making, 4, 280-286.

Flaherty, B. P., \& Kiff, C. J. (2012). Latent class and latent profile models. In H. Cooper, P. M. Camic, D. L. Long, A. T. Panter, D. Rindskopf \& K. J. Sher (Eds.), APA handbook of research methods in psychology (Vol. 3: Data analysis and research publication, pp. 391404). Washington, DC: American Psychological Association. 
Fleeson, W., \& Noftle, E. (2008). The end of the person-situation debate: An emerging synthesis in the answer to the consistency question. Social and Personality Psychology Compass, 2(4), 1667-1684.

Forsyth, D. R. (1980). A taxonomy of ethical ideologies. Journal of Personality and Social Psychology, 39, 175-184.

Fox, S., \& Spector, P. E. (Eds.). (2005). Counterproductive work behavior: Investigations of actors and targets. Washington, DC: American Psychological Association.

Fox, S., Spector, P. E., Goh, A., Bruursema, K., \& Kessler, S. R. (2012). The deviant citizen: Measuring potential positive relations between counterproductive work behaviour and organizational citizenship behaviour. Journal of Occupational and Organizational Psychology, 85(1), 199-220. doi: 10.1111/j.2044-8325.2011.02032.x

Freud, S. (1961). The ego and the id [original work published 1923-1925] (J. Strachey, Trans.). In J. Strachey (Ed.), The standard edition of the complete psychological works of Sigmund Freud (Vol. 19). London: Hogarth Press

Funder, D. C., \& Fast, L. A. (2010). Personality in social psychology. In S. T. Fiske, D. T. Gilbert \& G. Lindzey (Eds.), Handbook of Social Psychology (Vol. 5, pp. 668-697). New York: Wiley.

Funder, D. C., \& Ozer, D. J. (1983). Behavior as a function of the situation. Journal of Personality and Social Psychology, 44(1), 107-112. doi: 10.1037/0022-3514.44.1.107

Gilligan, C. (1982). In a different voice: Psychological theory and women's development. Cambridge: MA: Harvard University Press.

Gino, F., \& Ariely, D. (2012). The dark side of creativity: Original thinkers can be more 
dishonest. Journal of Personality and Social Psychology, 102(3), 445-459. doi: 10.1037/a0026406

Gino, F., Schweitzer, M. E., Mead, N. L., \& Ariely, D. (2011). Unable to resist temptation: How self-control depletion promotes unethical behavior. Organizational Behavior and Human Decision Processes, 115(2), 191-203. doi: 16/j.obhdp.2011.03.001

Graham, J., Haidt, J., \& Nosek, B. A. (2009). Liberals and conservatives rely on different sets of moral foundations. Journal of Personality and Social Psychology, 96(5), 1029-1046. doi: 10.1037/a0015141

Graham, J., Nosek, B. A., Haidt, J., Iyer, R., Koleva, S., \& Ditto, P. H. (2011). Mapping the moral domain. Journal of Personality and Social Psychology, 101(2), 366-385. doi: $10.1037 / \mathrm{a} 0021847$

Gray, K., Young, L., \& Waytz, A. (2012). Mind perception is the essence of morality. Psychological Inquiry, 23(2), 101-124. doi: 10.1080/1047840x.2012.651387

Greene, J. D. (2013). Moral tribes: emotion, reason, and the gap between us and them. New York: The Penguin Press.

Greene, J. D., Sommerville, R. B., Nystrom, L. E., Darley, J. M., \& Cohen, J. D. (2001). An fMRI investigation of emotional engagement in moral judgment. Science, 293(5537), 2105-2105.

Haidt, J. (2001). The emotional dog and its rational tail: A social intuitionist approach to moral judgment. Psychological Review, 108(4), 814-834.

Haidt, J. (2007). The new synthesis in moral psychology. Science, 316(5827), 998-1002.

Haidt, J. (2010). Moral psychology must not be based on faith and hope: Commentary on 
Narvaez (2010). Perspectives on Psychological Science, 5(2), 182-184. doi:

$10.1177 / 1745691610362352$

Haidt, J., \& Kesebir, S. (2010). Morality. In S. T. Fiske, D. T. Gilbert \& G. Lindzey (Eds.), Handbook of Social Psychology (Vol. 5, pp. 797-832). New York: Wiley.

Halevy, N., Cohen, T. R., Chou, E. Y., Katz, J. J., \& Panter, A. T. (2014). Mental models at work: Cognitive causes and consequences of conflict in organizations. Personality and Social Psychology Bulletin, 40(1), 92-110. doi: 10.1177/0146167213506468.

Hegarty, W. H., \& Sims, H. P. (1978). Some determinants of unethical decision behavior: An experiment. Journal of Applied Psychology, 63(4), 451-457. doi: 10.1037/00219010.63 .4 .451

Henle, C. A., \& Gross, M. A. (2013). Born to be deviant? An examination of the relationship between workplace deviance and employee personality. In S. M. Elias (Ed.), Deviant and criminal behavior in the workplace. New York: New York University Press.

Hershfield, H. E., Cohen, T. R., \& Thompson, L. (2012). Short horizons and tempting situations: Lack of continuity to our future selves leads to unethical decision making and behavior. Organizational Behavior and Human Decision Processes, 117, 298-310. doi: 10.1016/j.obhdp.2011.11.002

Hogan, R. (1973). Moral conduct and moral character: A psychological perspective. Psychological Bulletin, 79(4), 217-232. doi: 10.1037/h0033956

Hogan, R. (1975). The structure of moral character and the explanation of moral action. Journal of Youth and Adolescence, 4(1), 1-15.

Janoff-Bulman, R., \& Carnes, N. C. (2013). Surveying the Moral Landscape Moral Motives and 
Group-Based Moralities. Personality and Social Psychology Review. doi:

$10.1177 / 1088868313480274$

Kim, Y., Cohen, T. R., \& Panter, A. T. (2014, February). Reciprocal relationship between mistreatment and counterproductive work behavior: A twelve-wave longitudinal study. Poster presented at the annual meeting of the Society for Personality and Social Psychology, Austin, TX.

Kish-Gephart, J. J., Harrison, D. A., \& Treviño, L. K. (2010). Bad apples, bad cases, and bad barrels: Meta-analytic evidence about sources of unethical decisions at work. Journal of Applied Psychology, 95(1), 1-31. doi: 10.1037/a0017103

Kohlberg, L. (1969). Stage and sequence: The cognitive-developmental approach to socialization. In D. A. Goslin (Ed.), Handbook of socialization theory and research. Chicago: Rand McNally.

Kurtines, W. M. (1986). Moral behavior as rule governed behavior: Person and situation effects on moral decision making. Journal of Personality and Social Psychology, 50(4), 784791. doi: $10.1037 / 0022-3514.50 .4 .784$

Kray, L. J., \& Haselhuhn, M. P. (2007). Implicit negotiation beliefs and performance: Experimental and longitudinal evidence. Journal of Personality and Social Psychology, 93(1), 49-64. doi: 10.1037/0022-3514.93.1.49

Lee, K., \& Ashton, M. C. (2012). The H Factor of Personality: Why Some People are Manipulative, Self-Entitled, Materialistic, and Exploitive-And Why It Matters for Everyone. Waterloo, Canada: Wilfrid Laurier University Press.

Lee, K., Ashton, M. C., Morrison, D. L., Cordery, J., \& Dunlop, P. D. (2008). Predicting 
integrity with the HEXACO personality model: Use of self- and observer reports. Journal of Occupational and Organizational Psychology, 81, 147-167. doi: 10.1348/096317907X195175

Lewicki, R. J., Saunders, D. M., \& Barry, B. (2007). Negotiation: Readings, Exercises, and Cases (5 ed.). Boston: McGraw Hill / Irwin.

Linley, P. A., Maltby, J., Wood, A. M., Joseph, S., Harrington, S., Peterson, C., Park, N., \& Seligman, M. E. P. (2007). Character strengths in the United Kingdom: The VIA inventory of strengths. Personality and Individual Differences, 43(2), 341-351.

Marcus, B., Lee, K., \& Ashton, M. C. (2007). Personality dimensions explaining relationships between integrity tests and counterproductive behavior: Big five, or one in addition? Personnel Psychology, 60(1), 1-34.

Meier, L. L., \& Spector, P. E. (2013). Reciprocal Effects of Work Stressors and Counterproductive Work Behavior: A Five-Wave Longitudinal Study. Journal of Applied Psychology, No-Pagination Specified. doi: 10.1037/a0031732

Messick, D. M., \& McClintock, C. G. (1968). Motivational bases of choice in experimental games. Journal of experimental social psychology, 4(1), 1-25.

Mischel, W. (1968). Personality and Assessment. New York: Wiley.

Moore, C., Detert, J. R., Klebe Treviño, L., Baker, V. L., \& Mayer, D. M. (2012). Why Employees Do Bad Things: Moral Disengagement and Unethical Organizational Behavior. Personnel Psychology, 65(1), 1-48. doi: 10.1111/j.1744-6570.2011.01237.x

Murphy, R., Ackermann, K., \& Handgraaf, M. (2011). Measuring social value orientation. Judgment and Decision Making, 6, 771-781. 
Muthén, L. K., \& Muthén, B. O. (1998-2011). Mplus User's Guide (Sixth Edition). Los Angeles, CA.

Narvaez, D. (2010). Moral complexity: The fatal attraction of truthiness and the importance of mature moral functioning. Perspectives on Psychological Science, 5(2), 163-181. doi: $10.1177 / 1745691610362351$

Narvaez, D., \& Lapsley, D. K. (Eds.). (2009). Personality, Identity, and Character: Explorations in Moral Psychology. New York: Cambridge University Press.

O'Boyle, E. H., Jr., Forsyth, D. R., Banks, G. C., \& McDaniel, M. A. (2012). A meta-analysis of the Dark Triad and work behavior: A social exchange perspective. Journal of Applied Psychology, 97(3), 557-579. doi: 10.1037/a0025679

Ones, D. S., Viswesvaran, C., \& Schmidt, F. L. (1993). Comprehensive meta-analysis of integrity test validities: Findings and implications for personnel selection and theories of job performance. Journal of Applied Psychology, 78, 679-703.

Ones, D. S., Viswesvaran, C., \& Schmidt, F. L. (2012). Integrity tests predict counterproductive work behaviors and job performance well: Comment on Van Iddekinge, Roth, Raymark, and Odle-Dusseau (2012). Journal of Applied Psychology, 97(3), 537-542. doi:

$10.1037 / \mathrm{a} 0024825$

Ozer, D. J., \& Benet-Martínez, V. (2006). Personality and the Prediction of Consequential Outcomes. Annual Review of Psychology, 57(1), 401-421. doi: 10.1146/annurev.psych.57.102904.190127

Peterson, C., \& Seligman, M. E. P. (2004). Character strengths and virtues: A handbook and classification. USA: Oxford University Press. 
Piff, P. K., Stancato, D. M., Côté, S., Mendoza-Denton, R., \& Keltner, D. (2012). Higher social class predicts increased unethical behavior. Proceedings of the National Academy of Sciences. doi: 10.1073/pnas.1118373109

Podsakoff, P. M., MacKenzie, S. B., \& Organ, D. W. (2005). Organizational Citizenship Behavior: Its nature, antecedents, and consequences. Thousand Oaks, CA: SAGE Publications, Inc.

Rai, T. S., \& Fiske, A. P. (2011). Moral psychology is relationship regulation: Moral motives for unity, hierarchy, equality, and proportionality. Psychological Review, 118(1), 57-75. doi: 10.1037/a0021867

Raudenbush, S. W., Bryk, A. S., \& Congdon, R. (1996-2011). HLM 7: Hierarchical linear and nonlinear modeling [computer software]. Lincolnwood, IL: Scientific Software International, Inc.

Reed, A., \& Aquino, K. (2003). Moral identity and the expanding circle of moral regard toward out-groups. Journal of Personality and Social Psychology, 84(6), 1270-1286. doi: $10.1037 / 0022-3514.84 .6 .1270$

Reise, S. P., Moore, T. M., \& Haviland, M. G. (2010). Bifactor Models and Rotations: Exploring the Extent to Which Multidimensional Data Yield Univocal Scale Scores. Journal of Personality Assessment, 92(6), 544-559. doi: 10.1080/00223891.2010.496477

Rest, J. R. (1986). Moral development: Advances in research and theory. New York: Praeger.

Rest, J. R., Narvaez, D., Thoma, S. J., \& Bebeau, M. J. (1999). DIT2: Devising and testing a revised instrument of moral judgment. Journal of Educational Psychology, 91(4), 644659. doi: 10.1037/0022-0663.91.4.644 
Roberts, B. W., Jackson, J. J., Fayard, J. V., Edmonds, G., \& Meints, J. (2009).

Conscientiousness. In M. R. Leary \& R. H. Hoyle (Eds.), Handbook of Individual Differences in Social Behavior. New York: Guilford Press.

Roberts, B. W., Kuncel, N. R., Shiner, R., Caspi, A., \& Goldberg, L. R. (2007). The Power of Personality: The Comparative Validity of Personality Traits, Socioeconomic Status, and Cognitive Ability for Predicting Important Life Outcomes. Perspectives on Psychological Science, 2(4), 313-345. doi: 10.1111/j.1745-6916.2007.00047.x

Ross, L., \& Nisbett, R. E. (1991). The person and the situation: Perspectives of social psychology. New York: McGraw-Hill Book Company.

Sackett, P. R., \& Schmitt, N. (2012). On reconciling conflicting meta-analytic findings regarding integrity test validity. Journal of Applied Psychology, 97(3), 550-556. doi:

\section{$10.1037 / \mathrm{a} 0028167$}

Shao, R.D., Aquino K, Freeman D. (2008). Beyond moral reasoning: a review of moral identity research and its implications for business ethics. Business Ethics Quarterly, 18, 513-540.

Spector, P. E., Fox, S., Penney, L., Bruursema, K., Goh, A., \& Kessler, S. (2006). The dimensionality of counterproductivity: Are all counterproductive behaviors created equal? Journal of Vocational Behavior, 68(3), 446-460. doi: 10.1016/j.jvb.2005.10.005

Steinley, D., \& Brusco, M. J. (2011). Evaluating Mixture Modeling for Clustering: Recommendations and Cautions. Psychological Methods, 16(1), 63-79.

Stephan, W. G., \& Finlay, K. (1999). The role of empathy in improving intergroup relations. Journal of Social Issues, 55(4), 729-743.

Strathman, A., Gleicher, F., Boninger, D. S., \& Edwards, C. S. (1994). The consideration of 
future consequences: Weighing immediate and distant outcomes of behavior. Journal of Personality and Social Psychology, 66, 742-752.

Tangney, J. P., Baumeister, R. F., \& Boone, A. L. (2004). High self-control predicts good adjustment, less pathology, better grades, and interpersonal success. Journal of Personality, 72(2), 271-324. doi: 10.1111/j.0022-3506.2004.00263.x

Tangney, J. P., Stuewig, J., \& Martinez, A. G. (2014). Two faces of shame: The roles of shame and guilt in predicting recidivism. Psychological Science. doi: $10.1177 / 0956797613508790$

Tangney, J. P., Stuewig, J., \& Mashek, D. J. (2007). Moral emotions and moral behavior. Annual Review of Psychology, 58, 345-372.

Tangney, J. P., Youman, K., \& Stuewig, J. (2009). Proneness to shame and proneness to guilt. In M. R. Leary \& R. H. Hoyle (Eds.), Handbook of individual differences in social behavior (pp. 192-209). New York: Guilford.

Tenbrunsel, A. E., \& Smith-Crowe, K. (2008). Ethical decision making: Where we've been and where we're going. Academy of Management Annals, 2, 545-607.

Trautmann, S. T., Kuilen, G. v. d., \& Zeckhauser, R. J. (2013). Social Class and (Un)Ethical Behavior A Framework, With Evidence From a Large Population Sample. Perspectives on Psychological Science, 8(5), 487-497. doi: 10.1177/1745691613491272

Treviño, L. K., den Nieuwenboer, N. A., \& Kish-Gephart, J. J. (2014). (Un)Ethical Behavior in Organizations. Annual Review of Psychology, 65(1), 635-660. doi: 10.1146/annurevpsych-113011-143745

U.S. Bureau of Labor Statistics (2010). 2010 Standard Occupational Classification (SOC User 
Guide). Available from: http://www.bls.gov/soc/\#materials

Van Iddekinge, C. H., Roth, P. L., Raymark, P. H., \& Odle-Dusseau, H. N. (2012). The criterionrelated validity of integrity tests: An updated meta-analysis. Journal of Applied Psychology, 97(3), 499-530. doi: 10.1037/a0021196

Van Lange, P. A. M., Bekkers, R., Schuyt, T. N. M., \& Van Vugt, M. (2007). From games to giving: Social value orientation predicts donations to noble causes. Basic and Applied Social Psychology, 29(4), 375-384.

Vazire, S. (2010). Who knows what about a person? The self-other knowledge asymmetry (SOKA) model. Journal of Personality and Social Psychology, 98(2), 281-300. doi: $10.1037 / \mathrm{a} 0017908$

Wang, M., \& Hanges, P. J. (2011). Latent class procedures: Applications to organizational research. Organizational Research Methods, 14(1), 24-31. doi: $10.1177 / 1094428110383988$

Waytz, A., Dungan, J., \& Young, L. (2013). The whistleblower's dilemma and the fairnessloyalty tradeoff. Journal of Experimental Social Psychology, 49(6), 1027-1033. doi: 10.1016/j.jesp.2013.07.002

Zimbardo, P. G. (2004). A situationist perspective on the Psychology of Evil: Understanding How Good People Are Transformed into Perpetrators. In A. Miller (Ed.), The Social Psychology of Good and Evil: Understanding Our Capacity for Kindness and Cruelty. New York: Guilford. 


\section{Appendix}

\section{Moral Judgments of Workplace Behaviors Study}

We verified the assumption that $\mathrm{CWB}$ and $\mathrm{OCB}$ are reflective of unethical and ethical behavior in a study in which we surveyed a sample of 443 full-time employees from across the U.S. about the immorality versus morality of the 32 behaviors in the CWB-Checklist (Spector et al., 2006) and the 20 behaviors in the OCB-Checklist (Fox et al., 2012). Due to missing data, the analyses reported below are based on the data from 420 to 431 participants, depending on the item. These data were part of a larger study, part of which was reported in a previous paper (Cohen, Panter, \& Turan, 2013). The previous paper, however, did not include the following analyses.

Participants were presented with a randomized list of 52 work behaviors and were asked to indicate their opinion about whether each behavior is immoral or moral $(-3=$ extremely immoral, $-2=$ immoral, $-1=$ slightly immoral, $0=$ neutral,$+1=$ slightly moral,$+2=$ moral,$+3=$ extremely moral). Each of the $32 \mathrm{CWB}$ acts was judged immoral (significantly below the neutral midpoint, $p s<.001)$, ranging from slightly immoral for "ignoring someone at work" $(M=-.93$, $S D=1.17, t(425)=-16.43, p<.001)$ to immoral/extremely immoral for "threatening someone at work with violence" $(M=-2.43, S D=1.18, t(429)=-42.53, p<.001)$. Likewise, each of the 20 OCB acts was judged moral (significantly above the neutral midpoint, $p s<.001$ ), ranging from slightly moral for "giving up a meal and other breaks to complete work" $(M=1.04, S D=1.40$, $t(424)=15.26, p<.001)$ to moral for "going out of the way to give a coworker encouragement or express appreciation" $(M=2.01, S D=1.18, t(423)=35.05, p<.001)$. On average, the CWB acts were judged slightly to moderately immoral $(M=-1.85, S D=0.91, t(431)=-42.01, p<$ 
$.001)$ and the OCB acts were judged slightly to moderately moral $(M=1.68, S D=0.86, t(431)=$ 40.80, $p<.001)$. These findings support our operationalization of unethical/immoral work behavior as CWB and ethical/moral work behavior as OCB. 
Table 1. Kendall's tau-b correlations of individual differences with counterproductive work behavior (CWB) and organizational citizenship behavior (OCB) (Study $1 \&$ Study 2).

\begin{tabular}{|c|c|c|c|c|}
\hline & $\begin{array}{l}\text { CWB } \\
\text { week } 1 \\
\text { self-report } \\
(N=1072)\end{array}$ & $\begin{array}{l}\text { CWB } \\
\text { month } 1 \\
\text { coworker- } \\
\text { report } \\
(N=325)\end{array}$ & $\begin{array}{l}\text { OCB week } \\
1 \text { self- } \\
\text { report } \\
(N=947)\end{array}$ & $\begin{array}{l}\text { OCB } \\
\text { month } 1 \\
\text { coworker- } \\
\text { report } \\
(N=269)\end{array}$ \\
\hline 1. Honesty-Humility & $-.22 * *$ & $-.17 * *$ & $.06^{*}$ & $.20 * *$ \\
\hline 2. Emotionality & .04 & .06 & -.001 & -.04 \\
\hline 3. Extraversion & $-.15 * *$ & $-.13 *$ & $.14 * *$ & $.20 * *$ \\
\hline 4. Agreeableness & $-.14 * *$ & $-.17 * *$ & $.04 *$ & $.09 *$ \\
\hline 5. Conscientiousness & $-.22 * *$ & $-.13 * *$ & $.09 * *$ & $.23 * *$ \\
\hline 6. Openness to Experience & $-.12 * *$ & -.07 & $.12 * *$ & $.22 * *$ \\
\hline 7. Guilt Proneness & $-.17 * *$ & $-.19 * *$ & $.11 * *$ & $.22 * *$ \\
\hline 8. Guilt-Repair Orientation & $-.16^{* *}$ & -.08 & $.11 * *$ & $.23 * *$ \\
\hline 9. Shame Proneness & $-.09 * *$ & -.06 & $.07 *$ & .08 \\
\hline 10. Shame-Withdrawal Orientation & $.17 * *$ & $.11 *$ & -.01 & $-.11 *$ \\
\hline 11. Empathic Concern & $-.18 * *$ & $-.19 * *$ & $.09 * *$ & $.19 * *$ \\
\hline 12. Perspective Taking & $-.17 * *$ & $-.19 * *$ & $.13 * *$ & $.17 * *$ \\
\hline 13. Moral Identity-Internalization & $-.17 * *$ & $-.14 * *$ & $.08 * *$ & $.25 * *$ \\
\hline 14. Moral Identity-Symbolization & $-.07 *$ & -.03 & $.11 * *$ & $.14 * *$ \\
\hline 15. Cognitive Moral Development & -.03 & .004 & .04 & $.09 *$ \\
\hline 16. Moral Idealism & $-.10 * *$ & -.05 & $.10 * *$ & $.14 * *$ \\
\hline 17. Moral Relativism & $.11 * *$ & $.12 *$ & -.01 & -.05 \\
\hline 18. Consideration of Future & $-.16^{* *}$ & $-.11 *$ & $.11 * *$ & $.22 * *$ \\
\hline 19. Future Self-Continuity & $-.17 * *$ & $-.16^{* *}$ & -.01 & -.01 \\
\hline 20. Exploitiveness-Entitlement & $.19 * *$ & $.21 * *$ & -.02 & $.11 *$ \\
\hline 21. Self-Control (Study 2 only) ${ }^{a}$ & $-.31 * *$ & $-.26 * *$ & $.08 *$ & $.17 *$ \\
\hline 22. Machiavellianism (Study 2 only) ${ }^{\mathrm{a}}$ & $.25 * *$ & $.21 * *$ & $-.12 *$ & $-.20 *$ \\
\hline
\end{tabular}

Note. Data from Study 1 and Study 2 were combined when computing these correlations.

${ }^{a}$ The sample size for self-control and Machiavellianism was smaller than for the other variables $(N=$ 375 with self-reported CWB, $N=326$ with self-reported $\mathrm{OCB}, N=121$ with coworker-reported CWB and $N=98$ with coworker-reported OCB).

$* p<.05 ; * * p<.001$ 
Table 2. Multilevel models of self-reported counterproductive work behavior (CWB) and organizational citizenship behavior (OCB) during the past week for 12 consecutive weeks (Study $1 \&$ Study 2).

\begin{tabular}{|c|c|c|c|c|}
\hline & $\begin{array}{r}\text { Study } 1 \text { CWB } \\
(N=995)\end{array}$ & $\begin{array}{r}\text { Study } 2 \text { CWB } \\
(N=439)\end{array}$ & $\begin{array}{r}\text { Study } 1 \text { OCB } \\
(N=995)\end{array}$ & $\begin{array}{r}\text { Study } 2 \text { OCB } \\
(N=426)\end{array}$ \\
\hline Low Moral Character ${ }^{\mathrm{a}}$ & $0.89(.18) * *$ & $1.42(.19) * *$ & $-0.09(.10)$ & $0.02(.13)$ \\
\hline High Moral Character ${ }^{\mathrm{a}}$ & $-0.80(.14)^{* *}$ & $-0.55(.23) *$ & $0.10(.07)$ & $0.29(.10)^{*}$ \\
\hline Age (years) & $-.032(.007)^{* *}$ & $-0.030(.009) *$ & $.002(.003)$ & $0.001(.005)$ \\
\hline Income (natural log) & $-0.08(.11)$ & $-0.24(.16)$ & $-0.05(.05)$ & $-0.09(.08)$ \\
\hline Tenure at job (months) & $0.000(.001)$ & $0.000(.001)$ & $-0.000(.000)$ & $-0.000(.000)$ \\
\hline Job Satisfaction & $-0.15(.05) *$ & $-0.09(.07)$ & $0.07(.03)^{*}$ & $0.06(.04) \pm$ \\
\hline Female & $-0.17(.13)$ & $0.09(.18)$ & $-0.02(.07)$ & $0.14(.11)$ \\
\hline Bachelor's degree or more & $-0.07(.14)$ & $0.22(.17)$ & $-0.17(.07) *$ & $0.01(.09)$ \\
\hline Supervisor & $0.14(.13)$ & $0.50(.18) *$ & $0.38(.07)^{* *}$ & $0.33(.10)^{* *}$ \\
\hline Race: Black ${ }^{\mathrm{b}}$ & $0.27(.23)$ & $0.66(.31)^{*}$ & $-0.04(.14)$ & $0.11(.16)$ \\
\hline Race: Hispanic ${ }^{\mathrm{b}}$ & $0.49(.29) \pm$ & $0.09(.33)$ & $0.09(.17)$ & $0.16(.19)$ \\
\hline Race: $A \operatorname{sian}^{b}$ & $0.30(.32)$ & $-0.62(.67)$ & $-0.11(.21)$ & $-0.36(.38)$ \\
\hline Race: Other ${ }^{\mathrm{b}}$ & $0.31(.26)$ & $0.32(.32)$ & $-0.01(.15)$ & $0.04(.18)$ \\
\hline Code not enforced ${ }^{\mathrm{c}}$ & $0.38(.33)$ & $0.58(.41)$ & $0.19(.20)$ & $0.41(.26)$ \\
\hline Code loosely enforced $^{c}$ & $-0.14(.21)$ & $-0.34(.28)$ & $-0.08(.12)$ & $0.23(.17)$ \\
\hline Code strictly enforced ${ }^{\mathrm{c}}$ & $-0.27(.21)$ & $-0.32(.28)$ & $0.08(.12)$ & $0.20(.16)$ \\
\hline Doesn't know code: ${ }^{c}$ & $-0.39(.43)$ & $-0.29(.47)$ & $-0.24(.23)$ & $-0.48(.31)$ \\
\hline Non-profit sector ${ }^{\mathrm{d}}$ & $0.01(.19)$ & $-0.02(.25)$ & $0.06(.11)$ & $0.14(.14)$ \\
\hline Government sector ${ }^{\mathrm{d}}$ & $-0.14(0.19)$ & $0.13(.25)$ & $-0.16(.10) \pm$ & $-0.25(.13) \pm$ \\
\hline Self-employed $^{\mathrm{d}}$ & $0.52(.31) \pm$ & $0.04(.37)$ & $-0.29(.17) \pm$ & $-0.05(.21)$ \\
\hline Less than 20 employees ${ }^{\mathrm{e}}$ & $-0.65(.23)^{*}$ & $-0.36(.29)$ & $-0.30(.11)^{*}$ & $-0.10(.16)$ \\
\hline 20 to 99 employees $^{\mathrm{e}}$ & $-0.13(.19)$ & $-0.34(.24)$ & $-0.10(.10)$ & $-0.22(.13)$ \\
\hline 100 to 499 employees $^{\mathrm{e}}$ & $0.16(.17)$ & $-0.41(.22) \pm$ & $0.01(.09)$ & $-0.13(.13)$ \\
\hline Week number & $-0.04(.01)^{* *}$ & $-0.06(.02) *$ & $-0.04(.003)^{* *}$ & $-0.06(.01)^{* *}$ \\
\hline Intercept & $0.71(.26)^{*}$ & $0.10(.37)$ & $2.57(.14)^{* *}$ & $2.23(.20)^{* *}$ \\
\hline
\end{tabular}

Note. Unstandardized regression coefficients (with standard errors) are presented. ${ }^{\text {a }}$ The reference category for the moral character variables was the average-moral-character class. ${ }^{\mathrm{b}}$ The reference category for the race variables was White. ${ }^{c}$ The reference category for the ethics code variables was no ethics code. ${ }^{\mathrm{d}}$ The reference category for the organizational sector variables was the private for-profit sector. ${ }^{\mathrm{e}}$ The reference category for the organizational size variables was more than 500 employees. Bolded values represent statistically significant effects.

$\pm p<.10 ; * p<.05 ; * * p<.001$. 
Table 3. Negative binomial regression models of coworker-reported counterproductive work behavior (CWB) and organizational citizenship behavior (OCB) during the past month (Study 1 \& Study 2).

\begin{tabular}{|c|c|c|c|c|}
\hline & $\begin{array}{r}\text { Study } 1 \text { CWB } \\
(N=204)\end{array}$ & $\begin{array}{r}\text { Study } 2 \text { CWB } \\
(N=117)\end{array}$ & $\begin{array}{r}\text { Study } 1 \text { OCB } \\
(N=170)\end{array}$ & $\begin{array}{r}\text { Study } 2 \text { OCB } \\
(N=95)\end{array}$ \\
\hline Low Moral Character ${ }^{\mathrm{a}}$ & $0.76(.41) \pm$ & $2.27(.50)^{* * *}$ & $-0.38(.17)^{*}$ & $-0.17(.26)$ \\
\hline High Moral Character ${ }^{\mathrm{a}}$ & $-0.32(.32)$ & $0.27(.46)$ & $0.31(.12)^{*}$ & $0.38(.16) *$ \\
\hline Age (years) & $-0.025(.015) \pm$ & $-0.013(.019)$ & $-0.003(.006)$ & $0.008(.010)$ \\
\hline Income (natural log) & $0.13(.19)$ & $-0.63(.40)$ & $-0.24(.11)^{*}$ & $0.30(.18) \pm$ \\
\hline Tenure at job (months) & $-0.001(.002)$ & $-0.003(.002)$ & $-0.001(.001)$ & $-0.002(.001)^{*}$ \\
\hline Job Satisfaction & $0.14(.11)$ & $-0.21(.15)$ & $0.11(.04)^{*}$ & $-0.06(.05)$ \\
\hline Female & $0.10(.29)$ & $-0.19(.38)$ & $0.06(.13)$ & $-0.19(.17)$ \\
\hline Bachelor's degree or more & $-0.39(.29)$ & $0.34(.43)$ & $-0.14(.12)$ & $-0.39(.17)^{*}$ \\
\hline Supervisor & $-0.17(.26)$ & $0.30(.40)$ & $0.18(.12)$ & $-0.05(.15)$ \\
\hline Race: Black ${ }^{\mathrm{b}}$ & $-1.03(.36) *$ & $0.22(.66)$ & $-0.80(.29) *$ & $0.07(.30)$ \\
\hline Race: Hispanic ${ }^{\mathrm{b}}$ & $0.89(.84)$ & $1.14(.74)$ & $0.20(.28)$ & $-0.08(.38)$ \\
\hline Race: Asian $^{b}$ & $1.65(.56)^{*}$ & $-2.13(1.01) *$ & $0.17(.25)$ & $-0.31(.47)$ \\
\hline Race: Other ${ }^{b}$ & $-0.09(.51)$ & $-0.64(.55)$ & $0.27(.22)$ & $0.08(.23)$ \\
\hline Code not enforced ${ }^{\mathrm{c}}$ & $1.57(.84) \pm$ & $-0.50(1.09)$ & $0.52(.28) \pm$ & $-0.38(.38)$ \\
\hline Code loosely enforced $^{\mathrm{c}}$ & $0.76(.43) \pm$ & $-0.10(.60)$ & $-0.14(.21)$ & $-0.05(.33)$ \\
\hline Code strictly enforced ${ }^{c}$ & $0.32(.45)$ & $-0.56(.60)$ & $0.04(.18)$ & $-0.08(.29)$ \\
\hline Doesn't know code: ${ }^{c}$ & $-2.46(1.01)^{*}$ & $\mathrm{f}$ & $0.13(.28)$ & $\mathrm{f}$ \\
\hline Non-profit sector ${ }^{\mathrm{d}}$ & $0.26(.37)$ & $-0.51(.61)$ & $0.40(.18)^{*}$ & $0.18(.21)$ \\
\hline Government sector ${ }^{\mathrm{d}}$ & $0.41(.35)$ & $0.15(.60)$ & $-0.13(.24)$ & $0.27(.22)$ \\
\hline Self-employed $^{\mathrm{d}}$ & $0.72(.51)$ & $-0.66(.71)$ & $-0.09(.26)$ & $-0.90(.30)^{*}$ \\
\hline Less than 20 employees $^{\mathrm{e}}$ & $-0.63(.42)$ & $-0.30(.73)$ & $-0.13(.21)$ & $0.13(.22)$ \\
\hline 20 to 99 employees $^{\mathrm{e}}$ & $-0.18(.43)$ & $1.18(.43)^{*}$ & $0.12(.17)$ & $0.17(.21)$ \\
\hline 100 to 499 employees $^{\mathrm{e}}$ & $-0.27(.35)$ & $0.06(.61)$ & $0.01(.17)$ & $0.30(.21)$ \\
\hline Intercept & $-0.48(2.30)$ & $8.91(3.91)^{*}$ & $5.21(1.29)^{* *}$ & $0.58(1.82)$ \\
\hline Dispersion & $2.90(.37)^{* *}$ & $2.43(.45) * *$ & $0.53(.07)^{* *}$ & $0.50(.12)^{* *}$ \\
\hline
\end{tabular}

Note. Unstandardized regression coefficients (with standard errors) are presented. ${ }^{\text {a }}$ The reference category for the moral character variables was the average-moral-character class. ${ }^{\mathrm{b}}$ The reference category for the race variables was White. ${ }^{c}$ The reference category for the ethics code variables was no ethics code. ${ }^{\mathrm{d}}$ The reference category for the organizational sector variables was the private for-profit

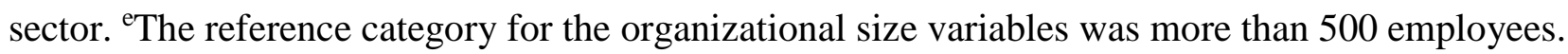
Bolded values represent statistically significant effects.

${ }^{\mathrm{f}}$ Parameter could not be estimated due to too few participants in that category $\pm p<.10 ; * p<.05 ; * * p<.001$ 
Table 4. Correlations of individual differences with delinquency and approval of unethical negotiation behaviors (Study 3).

\section{Correlation with Delinquency}

Correlation with Approval of Unethical Negotiation Behaviors

\begin{tabular}{lll}
\hline Honesty-Humility & $\mathrm{r}(460)=-.18, \mathrm{p}<.001$ & $\mathrm{r}(502)=-.48, \mathrm{p}<.001$ \\
Emotionality & $\mathrm{r}(460)=-.14, \mathrm{p}=.003$ & $\mathrm{r}(502)=-.08, \mathrm{p}=.09$ \\
Extraversion & $\mathrm{r}(460)=-.06, \mathrm{p}=.17$ & $\mathrm{r}(502)=-.14, \mathrm{p}=.002$ \\
Agreeableness & $\mathrm{r}(460)=-.21, \mathrm{p}<.001$ & $\mathrm{r}(502)=-.24, \mathrm{p}<.001$ \\
Conscientiousness & $\mathrm{r}(460)=-.11, \mathrm{p}=.02$ & $\mathrm{r}(502)=-.35, \mathrm{p}<.001$ \\
Openness to Experience & $\mathrm{r}(460)=.06, \mathrm{p}=.18$ & $\mathrm{r}(502)=-.11, \mathrm{p}=.01$ \\
Moral Identity-Internalization & $\mathrm{r}(464)=-.12, \mathrm{p}=.01$ & $\mathrm{r}(504)=-.41, \mathrm{p}<.001$ \\
Guilt Proneness & $\mathrm{r}(461)=-.13, \mathrm{p}=.005$ & $\mathrm{r}(503)=-.43, \mathrm{p}<.001$ \\
Guilt Repair Orientation & $\mathrm{r}(461)=-.14, \mathrm{p}=.002$ & $\mathrm{r}(503)=-.35, \mathrm{p}<.001$ \\
Empathic Concern & $\mathrm{r}(464)=-.22, \mathrm{p}<.001$ & $\mathrm{r}(503)=-.36, \mathrm{p}<.001$ \\
Perspective Taking & $\mathrm{r}(464)=-.12, \mathrm{p}=.01$ & $\mathrm{r}(503)=-.28, \mathrm{p}<.001$ \\
Consideration of Future Consequences & $\mathrm{r}(460)=-.05 ., \mathrm{p}=.25$ & $\mathrm{r}(501)=-.35, \mathrm{p}<.001$ \\
Self-Control & $\mathrm{r}(462)=-.22, \mathrm{p}<.001$ & $\mathrm{r}(503)=-.22, \mathrm{p}<.001$ \\
Machiavellianism & $\mathrm{r}(461)=.23, \mathrm{p}<.001$ & $\mathrm{r}(502)=.44, \mathrm{p}<.001$ \\
Narcissism & $\mathrm{r}(428)=.17, \mathrm{p}<.001$ & $\mathrm{r}(465)=.28, \mathrm{p}<.001$ \\
Moral Disengagement & $\mathrm{r}(460)=.13, \mathrm{p}=.004$ & $\mathrm{r}(503)=.51, \mathrm{p}<.001$ \\
Social Value Orientation (altruistic) & $\mathrm{r}(419)=.09, \mathrm{p}=.08$ & $\mathrm{r}(457)=-.14, \mathrm{p}=.004$ \\
Harm Moral Foundation & $\mathrm{r}(410)=-.11, \mathrm{p}=.03$ & $\mathrm{r}(446)=-.23, \mathrm{p}<.001$ \\
Fairness Moral Foundation & $\mathrm{r}(410)=-.10, \mathrm{p}=.046$ & $\mathrm{r}(446)=-.19, \mathrm{p}<.001$ \\
Ingroup Moral Foundation & $\mathrm{r}(410)=-.09, \mathrm{p}=.09$ & $\mathrm{r}(446)=.03, \mathrm{p}<.001$ \\
Authority Moral Foundation & $\mathrm{r}(410)=-.12, \mathrm{p}=.02$ & $\mathrm{r}(446)=-.09, \mathrm{p}=.047$ \\
Purity Moral Foundation & $\mathrm{r}(410)=-.15, \mathrm{p}=.003$ & $\mathrm{r}(446)=-.12, \mathrm{p}=.009$ \\
\hline
\end{tabular}


Table 5. Regression models of delinquency and approval of unethical negotiation behaviors (Study 3).

\begin{tabular}{|c|c|c|}
\hline & $\begin{array}{r}\text { Delinquency } \\
(\mathrm{N}=497)\end{array}$ & $\begin{array}{l}\text { Approval of Unethical } \\
\text { Negotiation Behaviors } \\
\qquad(\mathrm{N}=533)\end{array}$ \\
\hline Low Moral Character ${ }^{\mathrm{a}}$ & $0.22(0.08) *$ & $0.82(0.14) * *$ \\
\hline High Moral Character ${ }^{\mathrm{a}}$ & $-0.09(0.06) \pm$ & $-0.72(0.10)^{* * *}$ \\
\hline Age (years) & $0.000(0.002)$ & $-0.010(0.003) *$ \\
\hline Income $^{b}$ & $0.008(0.02)$ & $0.05(0.03)$ \\
\hline Female & $-0.11(0.06) \pm$ & $-0.21(0.10)^{*}$ \\
\hline Bachelor's degree or more & $0.02(0.06)$ & $-0.03(0.10)$ \\
\hline Race: Black ${ }^{\mathrm{c}}$ & $0.09(0.08)$ & $0.26(0.15) \pm$ \\
\hline Race: Hispanic ${ }^{c}$ & $0.19(0.11)$ & $0.13(0.21)$ \\
\hline Race: Asian ${ }^{c}$ & $-0.17(0.17)$ & $-0.02(0.32)$ \\
\hline Race: Other ${ }^{\mathrm{c}}$ & $-0.10(0.10)$ & $0.17(0.16)$ \\
\hline Intercept & $0.03(0.13)$ & $3.03(0.24) * *$ \\
\hline
\end{tabular}

Note. Unstandardized regression coefficients (with standard errors) are presented

${ }^{a}$ The reference category for the moral character variables was the average-moral-character class.

b Income was assessed in $\$ 25,000$ units, with 9 ordinal categories: $1=\$ 0$ to $\$ 25,000 ; 9=\$ 200,001$ or more.

${ }^{\mathrm{c}}$ The reference category for the race variables was White.

$\pm p<.10 ; * p<.05 ; * * p<.001$

Bolded values represent statistically significant effects. 


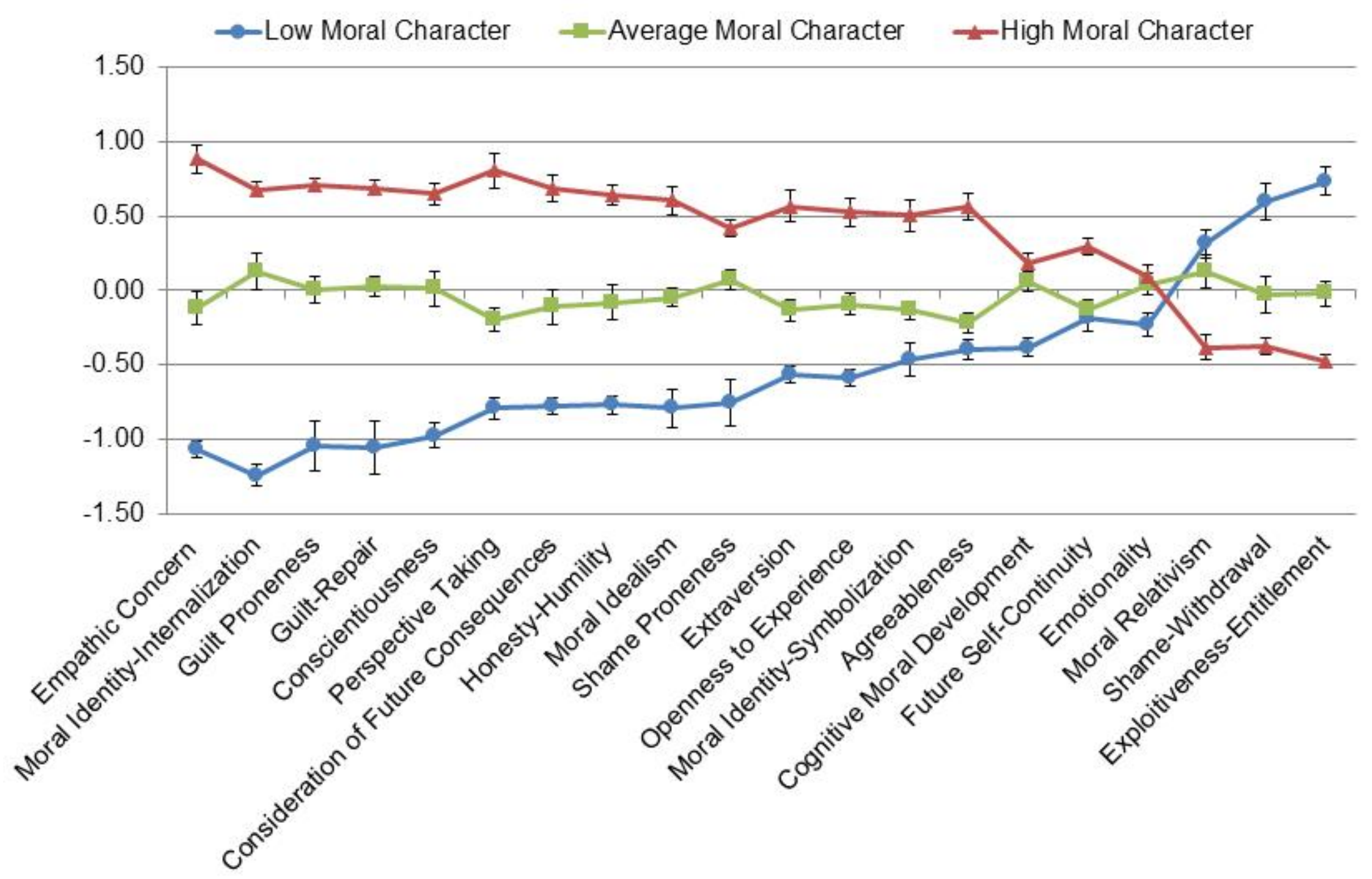

Figure 1. Study $1(N=1020)$ : Moral character latent profile model. Values represent the average standardized score for each variable for each latent class. Error bars denote one standard error above and below the latent class mean. 22.35\% of respondents were classified as low moral character, $44.71 \%$ as average moral character, and $32.94 \%$ as high moral character. 


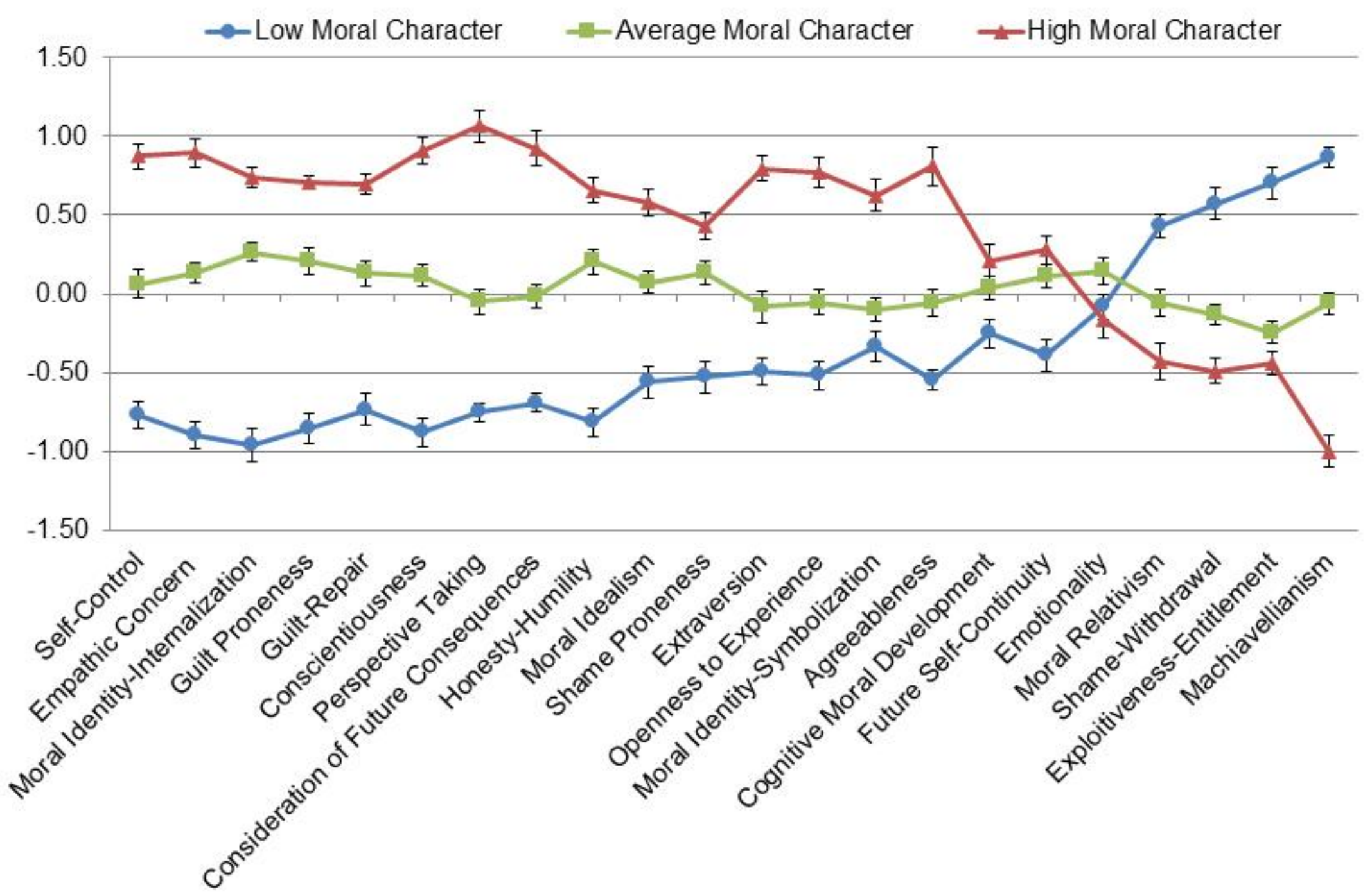

Figure 2. Study $2(N=494)$ : Moral character latent profile model. Values represent the average standardized score for each variable in each latent class. Error bars denote one standard error above and below the latent class mean. $30.57 \%$ of respondents were classified as low moral character, $46.36 \%$ as average moral character, and $23.08 \%$ as high moral character. 


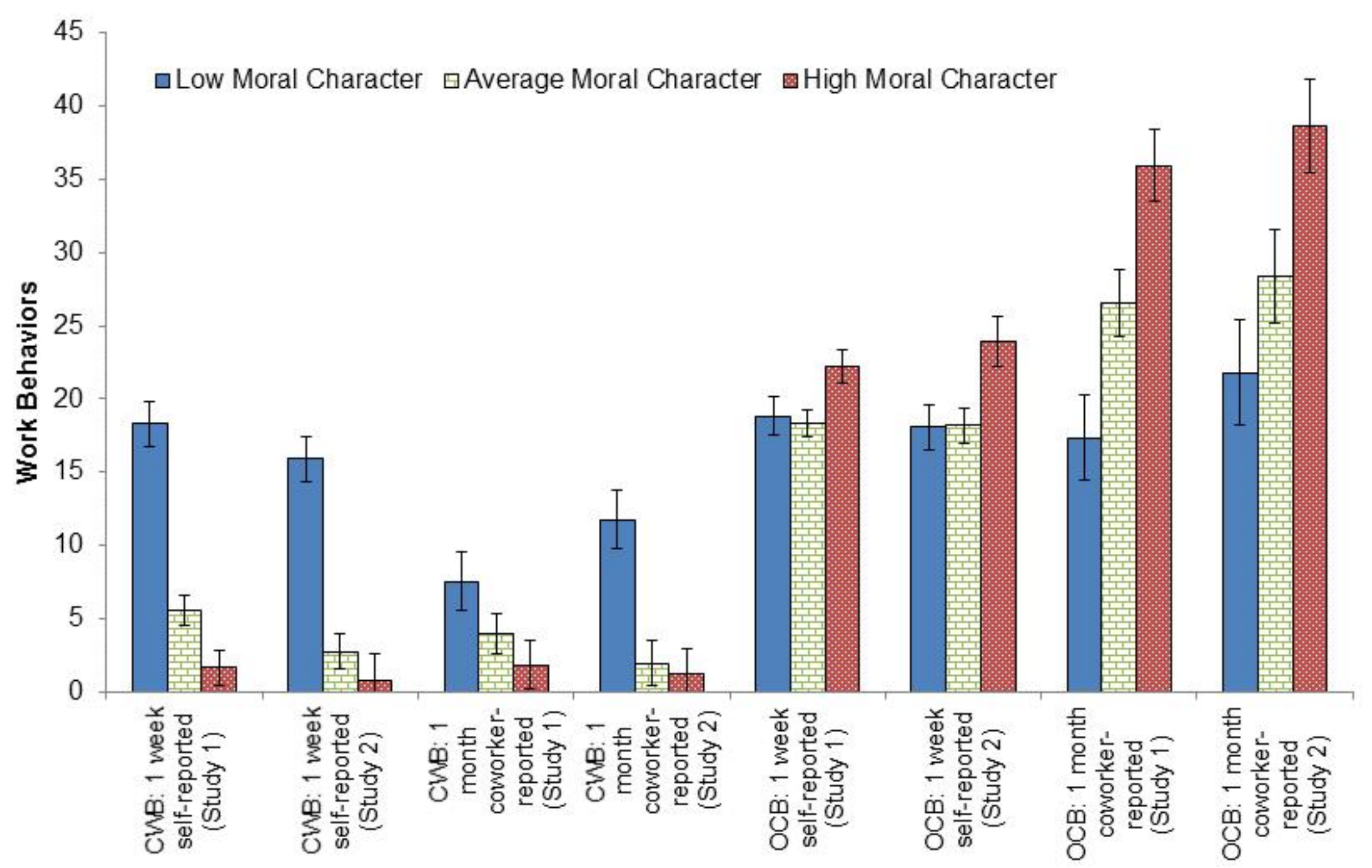

Figure 3. Study 1 and Study 2: Counterproductive work behavior (CWB) and organizational citizenship behavior (OCB) among employees low, average, and high in moral character. Error bars denote one standard error above and below the sample mean. 


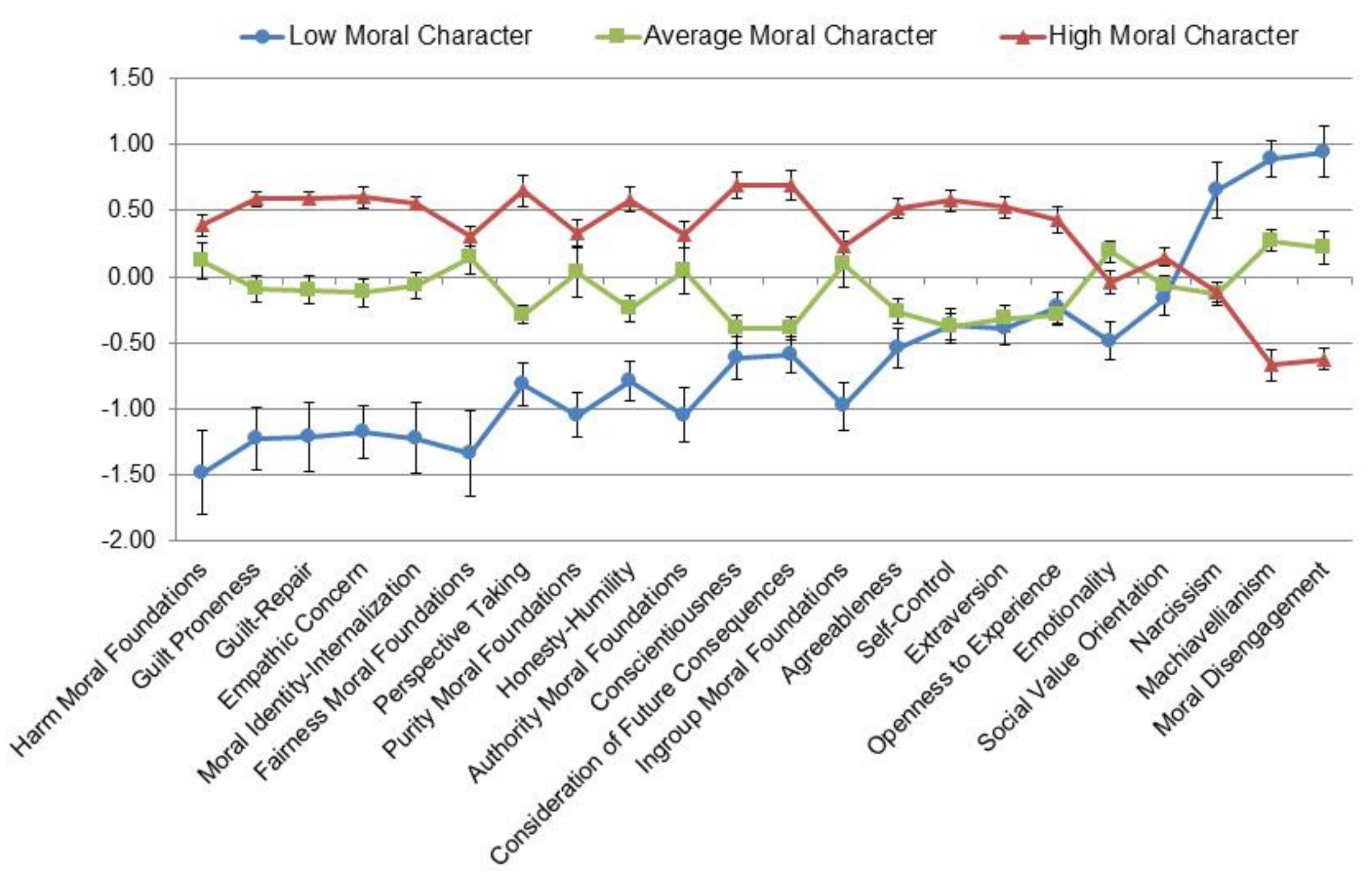

Figure 4. Study $3(N=659)$ : Moral character latent profile model. Values represent the average standardized score for each variable in each latent class. Error bars denote one standard error above and below the latent class mean. $15.59 \%$ of respondents were classified as low moral character, $45.40 \%$ as average moral character, and $39.01 \%$ as high moral character. 


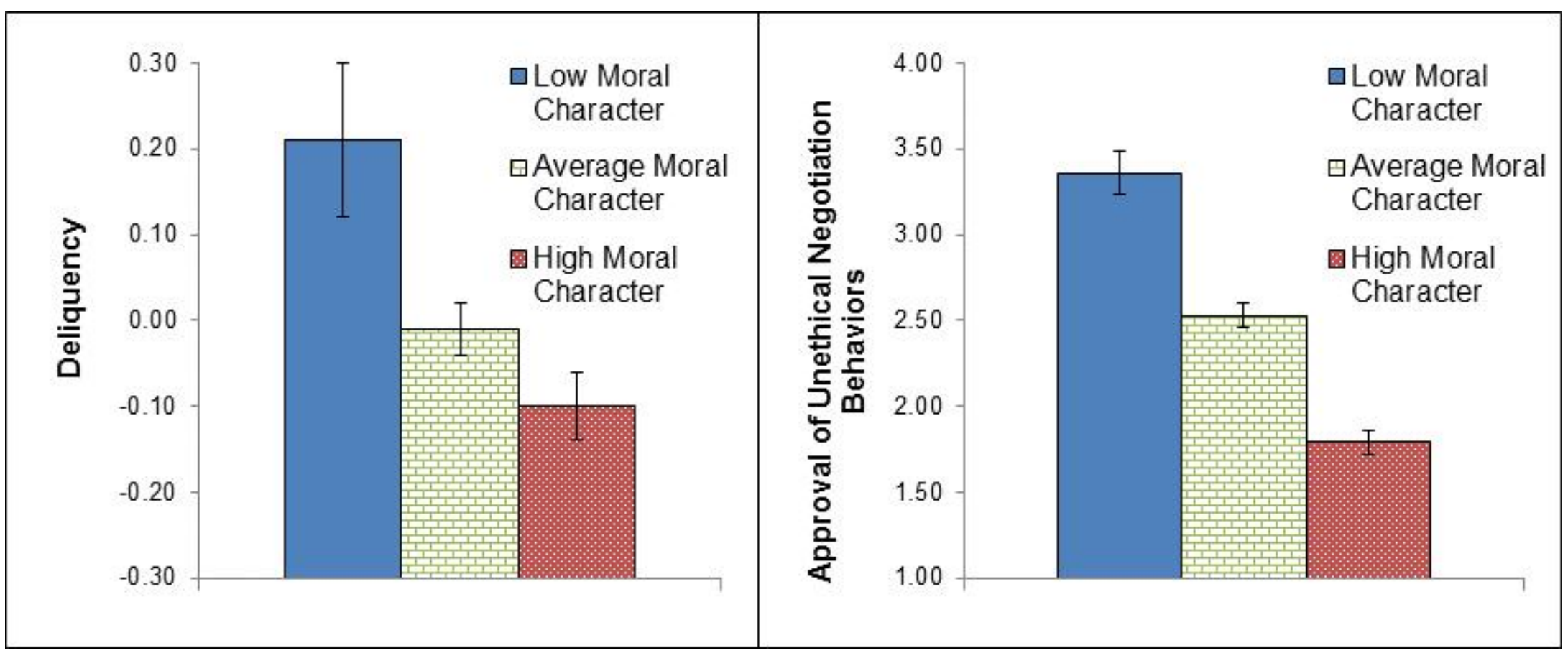

Figure 5. Study 3: Delinquency (left panel, $N=534$ ) and approval of unethical negotiation behaviors (right panel, $N=569$ ) among participants low, average, and high in moral character. Error bars denote one standard error above and below the sample mean. Positive delinquency scores indicate more delinquency than the average participant and negative delinquency scores indicate less delinquency than the average participant. Approval of unethical negotiation behaviors could range from 1 (tactic regarded as very inappropriate) to 7 (tactic is regarded as very appropriate), with the midpoint (4) indicative of neutral. 


\section{Footnotes}

${ }^{1}$ The supplemental online materials include results from exploratory factor analyses, principal components analyses, and latent profile analyses.

2 Two recent articles have used data from the WECT Project to investigate different research questions from those addressed here (Cohen, Panter, Turan, Morse, \& Kim, 2013; Halevy, Cohen, Chou, Katz, \& Panter, 2014). The first article examined similarity and self-other agreement of guilt proneness, shame proneness, and the HEXACO factors (Cohen, Panter, Turan, et al., 2013, Study 2). The second article examined the relationship between mental models of conflict and organizational mistreatment (Halevy et al., 2014, pp., Study 4). The current research focuses on a broader set of variables than the prior papers, and the analyses and results we report here do not overlap with the prior work.

${ }^{3}$ Due to an error by the survey research firm, participants who missed a weekly survey in Study 1 were not sent survey invitations in subsequent weeks. This error was discovered in week 10. After this discovery, all participants were sent invitations for the remaining surveys. Because of the error, many of the weekly surveys in Study 1 were sent to only a subset of participants, which compromises the generalizability of the data from those weekly assessments. We conducted Study 2 to address this sampling problem. In Study 2, all participants who completed the initial survey were sent subsequent survey invitations each week. We used the missing data option in MPlus (Muthén \& Muthén, 1998-2011) to utilize all available data when conducting the latent profile analyses and negative binomial regression models. 
${ }^{4}$ Study 3 also included two scales related to negotiation that were not relevant to the current investigation of moral character traits. These were Halevy et al.'s (2014) measure of conflict mental models and Kray and Haselhuhn's (2007) measure of implicit negotiation beliefs. Information about these measures is available upon request.

${ }^{5}$ The new item is: Out of frustration, you break the photocopier at work. Nobody is around and you leave without telling anyone. What is the likelihood you would feel bad about the way you acted? 